\title{
Integrated Control and Display Research for Transition and Vertical Flight on the NASA V/STOL Research Aircraft (VSRA)
}

John D. Foster

Ernesto Moralez III

James A. Franklin, Ames Research Center, Moffett Field, California

Jeffery A. Schroeder, Aeroflightdynamics Directorate, U.S. Army Aviation Research and Technology Activity, Ames Research Center, Moffett Field, California

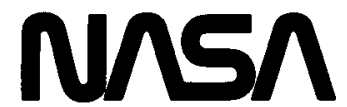

National Aeronautics and Space Administration 


\title{
INTEGRATED CONTROL AND DISPLAY RESEARCH FOR TRANSITION AND VERTICAL FLIGHT ON THE NASA V/STOL RESEARCH AIRCRAFT (VSRA)
}

\author{
John D. Foster, Ernesto Moralez III, and James A. Franklin \\ Ames Research Center \\ Jeffery A. Schroeder \\ Aeroflightdynamics Directorate \\ U.S. Army Aviation Research and Technology Activity \\ Ames Research Center
}

\begin{abstract}
Results of a substantial body of ground-based simulation experiments indicate that a high degree of precision of operation for recovery aboard small ships in heavy seas and low visibility with acceptable levels of effort by the pilot can be achieved by integrating the aircraft flight and propulsion controls. The availability of digital fly-by-wire controls makes it feasible to implement an integrated control design to achieve and demonstrate in flight the operational benefits promised by the simulation experience. It remains to validate these systems concepts in flight to establish their value for advanced short takeoff vertical landing (STOVL) aircraft designs. This paper summarizes analytical studies and simulation experiments that provide a basis for the flight research program that will develop and validate critical technologies for advanced STOVL aircraft through the development and evaluation of advanced, integrated control and display concepts and lays out the plan for the flight program that will be conducted on NASA's V/STOL Research Aircraft (VSRA).
\end{abstract}

\section{INTRODUCTION}

There continues to be a recognition by the U.S. military of a need for supersonic, high-performance aircraft that have vertical landing capabilities. The U.S. Air Force has acknowledged the problem of runway denial and its effect on mission performance and has reemphasized, in their Forecast II strategic planning, the need for aircraft which have the capability of landing vertically. The Navy and Marine Corps have had a continuing interest for over 15 years in the use of V/STOL or STOVL aircraft for small ship operations; in particular, it can be presumed that operational deployment of the V-22 Osprey will provide demonstration of the benefits these services have predicted and will lead to a requirement for a new class of medium speed V/STOL machines in addition to the continuing Marine requirement for V/STOL fighter-class aircraft.

Control requirements for V/STOL aircraft are predicated on the operational environment to which they are exposed. For military use, these aircraft may be required to operate from conventional airfields, austere sites, aircraft carriers or small aviation capable vessels (fig. 1). The capability for hover and low-speed flight and for rapidly transitioning between wing-borne and propulsion-borne flight permits V/STOL aircraft to operate into confined spaces associated with austere sites and decks of small ships. In principle, V/STOL aircraft should be able to accomplish these operations under weather conditions which would be prohibitive for conventional aircraft. However, these operations enforce precision of control of position, velocity, and attitude, the ability to quickly arrest closure rates in tight spaces, and to do so under conditions of winds, turbulence, and low visibility; such requirements exceed those imposed on conventional fixed-wing counterparts to a considerable degree. For example, operations at forward land bases may be conducted from 70-ft $x$ 70-ft temporary pads in close proximity to trees and other obstacles or on amphibious assault ships or destroyers on a small pad near the ship's superstructure. During recovery to the ship, the heave, sway, and rolling motion of the landing pad may present a significant control challenge for the pilot (fig. 2). Currently, the shipboard capability of fixed-wing V/STOL aircraft involves constant-speed stabilized descents in instrument meteorological conditions (IMC) to a minimum altitude of $300 \mathrm{ft}$, followed by deceleration to 
hover in visual meteorological conditions (VMC) with at least 1-mile visual range. Recovery to the ship is restricted to landing areas at least the size provided by amphibious assault ships (LPH-type Iwo Jima-class or LHA-type Tarawa-class) and in sea state 3 or less.

A major technological challenge to routine vertical flight operations of this class of aircraft in adverse weather and low-visibility conditions stems from the complex interaction of kinematics, aerodynamics, and propulsive forces and moments during the conversion from airborne to jetborne flight as reflected in poor flying qualities as well as from limited control authorities. The pilot's control problem is aggravated by the generally degraded flying qualities encountered as the dependence on powered lift increases and by an additional control requirement related to the conversion from forward flight to powered lift (e.g., thrust vectoring, ignition of or flow switching to lift augmenting devices). Accordingly, means to integrate the propulsive and aerodynamic controls and displays in ways which minimize the design requirements for excessive propulsive capability (e.g., bleed-air requirements) and yet which provide enhanced flightpath precision and mission capability in adverse weather must be found.

During the past two decades, several experimental and operational programs were conducted to determine these control and display requirements for V/STOL aircraft performing instrument transition in the terminal area. Early work in both areas led to the classic NATO Advisory Group for Aerospace Research and Development (AGARD) Advisory Report on V/STOL display requirements for landing (ref. 1), which pointed out that the interplay between required control and display complexities was of fundamental importance to determining operational capability. Since that time, the advent of increased poor weather operation of helicopters to small platforms, of demonstrated flight capabilities of the tilt-rotor aircraft, and of expanded military uses of vectored-thrust, fixed-wing, V/STOL aircraft have concentrated recent research efforts specifically on these classes of aircraft. For example, significant effort has been devoted to extending operational capability aboard ship to include recovery in adverse weather and heavy seas to small vessels such as frigates and destroyers. Results of a substantial body of ground-based simulation experiments indicate that a high degree of precision of operation for recovery aboard small ships in heavy seas and low visibility with acceptable levels of effort by the pilot can be achieved by integrating the aircraft flight and propulsion controls. The integration of controls significantly improves the basic aircraft response to pilot commands for attitude, height, and position control, without increasing reaction control system demands for engine bleed flow. This benefit is crucial for future supersonic STOVL aircraft since reaction control air requirements have a significant effect on engine size.

The availability of digital fy-by-wire controls makes it feasible to implement an integrated control design to achieve and demonstrate in flight the operational benefits promised by the simulation experience. It remains to validate these systems concepts in flight to establish their value for advanced STOVL aircraft designs. This paper describes the overall plan for a flight research program that will develop and validate critical technologies for advanced STOVL aircraft through the development and evaluation of advanced, integrated control and display concepts. The program will be conducted on NASA Ames Research Center's VSRA, which is a modified version of the YAV-8B Harrier prototype aircraft. The paper also summarizes analytical studies and simulation experiments that provide a basis for the flight research program and lays out the plan for the flight program itself.

\section{SIMULATION EXPERIENCE}

\section{Simulation Facility}

The data that are summarized here come from programs conducted on Ames Research Center's Vertical Motion Simulator (VMS) during the past six years to support the development of advanced fixed-wing $\mathrm{V} / \mathrm{STOL}$ control and display concepts for shipboard operations (fig. 3 ). The VMS has a complex movable structure to provide six-degree-of-freedom motion that includes large vertical and longitudinal travel of $\pm 23 \mathrm{ft}$ and $\pm 15 \mathrm{ft}$, respectively, to enhance fidelity of the vertical and longitudinal motions, which are particularly important for the transition and hover. The visual display consists of a four window, computer-generated image that modeled a DD-963-type, Spruance-class destroyer with a 40-ft x 70-ft landing pad. Instrument conditions simulated fog as a function of ceiling and visual range on the computer-generated imagery. 
Evaluation tasks included lateral offset captures of the final approach, deceleration on a descending path in IMC, and a final visual landing segment. A $100-\mathrm{ft}$ ceiling and $700-\mathrm{ft}$ visual range was used, so that the deceleration to the hover point took place entirely on instruments. The landing consisted of a horizontal translation from the hover point to the recovery area on the ship and a vertical descent to the landing pad (fig. 4) under visual conditions. The environmental situation and resulting ship motion were important additional task variables. Three different environmental conditions were represented that can be generally associated with sea state (fig. 2). Sea state 0 corresponded to no ship motion with 15 knots wind over deck from $30^{\circ}$ to port. Sea state 4 involved moderate deck motion (peak excursions of $7 \mathrm{ft}$ heave, $2 \mathrm{ft}$ sway, and $3^{\circ}$ roll at the landing pad) and a wind of 34 knots. Sea state 6 produced extensive deck motion $(17 \mathrm{ft}$ heave, $6 \mathrm{ft}$ sway, and $10^{\circ}$ roll) in a wind of 43 knots. The primary source of data in all the experiments was pilot comments and ratings (ref. 2). Evaluations typically involved at least two full approaches. Six pilots participated in the experiments.

\section{Control and Display Concepts}

The baseline aircraft configuration used for the experiments was the AV-8A Harrier, equipped with rate damping augmentation in pitch, roll, and yaw. Conventional center stick, pedals, throttle, and thrust vector angle (nozzle) levers comprised the pilot's control inceptors. A hierarchy of stabilization and command control augmentation modes was added to this baseline configuration through a full-authority, five-axis, fly-by-wire control system. The augmentation modes included attitude command in pitch and roll, attitude command with flightpath and longitudinal acceleration command, and attitude command with three-axis velocity command. Rate command systems were designed with time constants from 0.25 to $0.35 \mathrm{sec}$. Attitude command was designed to provide a second-order natural frequency of $2 \mathrm{rad} / \mathrm{sec}$ at a damping ratio of 1.0. For the transition, flightpath command combined with longitudinal acceleration command, both used in conjunction with the attitude command system, permitted the pilot to control flightpath for precision approach path tracking while independently commanding deceleration (or acceleration) along the path. Complicated manipulation of thrust and thrust vector controls in combination with adjustments in aircraft attitude for configuration management through transition and for path tracking was eliminated. The pilot was provided with individual inceptors for control of flightpath and longitudinal acceleration. Flightpath and longitudinal acceleration (or airspeed) responses were decoupled; flightpath response to its primary control was characterized by a first-order time constant of $1.1 \mathrm{sec}$ throughout transition.

Decoupled velocity command was used for the shipboard landing. Two methods of implementing horizontal velocity commands were provided; one method involved longitudinal and lateral control by modulating pitch and roll attitude through the attitude command system much as the pilot performs translational control with aircraft attitude. For this system, the pilot's control inceptors commanded translational rate directly. The alternate method provided longitudinal velocity control by modulating the thrust vector angle while keeping a fixed pitch attitude. In either case, vertical velocity command was implemented by modulating thrust. For velocity command through pitch and roll, translational rate response was related to its primary inceptor by a third-order binomial function of frequency $1.75 \mathrm{rad} / \mathrm{sec}$. When longitudinal velocity was controlled with thrust vector angle, translational rate followed the primary inceptor command with a 0.8-sec time constant. Vertical velocity response was characterized by a 1.1-sec time constant to its primary control.

A variety of display information levels were investigated using integrated electronic display units with command and status data presented either head-up or head-down. Transition displays were either of the situation/director type or of a flightpath centered pursuit type. The situation/director display (fig. 5a) was a three-cue compensatory flight director supplemented by situation information presented in both analog and digital format that included aircraft attitude and velocity states, altitude, position, velocity with respect to the intended hover point, thrust setting, and thrust vector angle. The flightpath pursuit/situation display (fig. 5b) which was conformal with the outside scene as viewed through the Head-Up Display (HUD), was intended to enhance the external visual cues, center them on the aircraft's flightpath, and present the pilot with a pursuit tracking task for following the intended transition and approach profile to the final hover point. The pursuit task represented loose formation flight on a lead (ghost) aircraft that is following the 
desired flight profile. Situation information that accompanies the flightpath and ghost aircraft symbology include aircraft attitude, speed, altitude, thrust, and thrust vector angle. The relation of the pilot's control inceptors to the primary controlled elements of the two displays is provided in figure 5 . For the vertical landing on the ship, the head-up display that was used in conjunction with these control modes is shown in figure 6. It is also a pursuit tracking display that combines command and situation information in the horizontal and vertical planes. Position and velocity of the aircraft with respect to the landing pad are presented and used by the pilot to translate to a position over the landing pad and to descend to landing. Attitude, airspeed, thrust setting, thrust vector angle, and vertical velocity limits are provided as situation information. More detailed descriptions of the controls and displays used for these experiments can be found in references 3-6.

\section{Summary of Results}

The collection of results of these V/STOL simulations for transition, hover and landing, forms the basis for a generalized view of the contribution of control augmentation and cockpit displays on operational capability of these aircraft in adverse weather from land bases or aboard ship. For the IMC decelerating approach, a summary of the Ames VMS simulator data is shown in figure 7. It is clear that the requirement for thrust vectoring V/STOL aircraft to change configuration in order to perform the deceleration demands a higher level of control augmentation than is necessary for fixed thrust vector aircraft like helicopters (ref. 7). When configuration changes are not required for the transition, an attitude command system is sufficient to provide at least marginally satisfactory flying qualities for the IMC deceleration. Vectored thrust aircraft need assistance with the thrust vector control, and these data indicate that flightpath and acceleration/deceleration command augmentation combined with the appropriate electronic display format provide a suitable means to achieve a similarly good level of flying qualities. Results of the ground-based simulator experiments for fixed-wing, vectored thrust V/STOL aircraft and helicopters (refs. 8,9) and from the flight data acquired from the Navy/Calspan X-22A (refs. 10,11) and the NASA/Army CH-47B (refs. 12,13) support these trends.

For vertical landing, the benefits of control augmentation depend on the size of the area in which the landing maneuvers must be confined and the amount of motion of the landing pad for operation aboard ship (fig. 8). Visual landing on a large fixed pad can be accomplished with at least adequate or even marginally satisfactory flying qualities with only rate damping augmentation based on the experience of several simulation and flight programs (refs. 14-21). For moderate size ships with little or no deck motion, an attitude command system will assure satisfactory flying qualities and rate augmentation will be adequate. Operational experience with AV-8A, GR Mk 3, and AV-8B Harriers indicate that these conclusions are probably conservative; rate command may also be satisfactory under these circumstances. When recovery is made to a ship as small as a DD-963-type, the control augmentation required is strongly dependent on sea condition. These simulation data indicate that for fully satisfactory flying qualities, velocity command augmentation is required even in calm seas. An attitude command system would be marginally satisfactory in this condition. In moderate seas, velocity command is still satisfactory, while attitude command is only adequate and a rate command system is borderline inadequate to accomplish the task. Even in heavy seas, the velocity command system can provide marginally satisfactory flying qualities, while the attitude system is borderline inadequate and the rate command system is clearly inadequate.

\section{VSRA RESEARCH SYSTEM DESIGN}

Given the potential improvement in control of V/STOL aircraft indicated by these simulation results, the NASA VSRA is being prepared to substantiate these benefits in flight. In particular, attention is being centered on validation of results for approach and vertical landing on destroyer-sized ships operating in high seas under conditions of poor visibility.

It was assumed throughout the previous simulation activities that the control system for advanced V/STOL aircraft would be digital, fly-by-wire with high-bandwidth, full-authority actuators. A major problem is that such a control system - with all its implied safety-mandated redundancy - would be prohibitively expensive to install in the VSRA. However, since the VSRA is aimed at investigating primarily 
low-speed maneuvering and regulatory tasks restricted to the partial and full-powered-lift flight envelope, it was conjectured that it may be possible to exploit the task restrictions by modifying the VSRA control system in a way that would provide a safe and acceptably capable system within budgetary constraints.

A modification to the existing VSRA control system is described which has the potential to achieve the control improvements demonstrated in the simulation experiments. Economy is achieved with this system by reducing the need for high redundancy. Catastrophic hard-overs are avoided by using high-rate, low-authority series-servo response for stabilization, and low-rate, high-authority parallel-servo response for either moderate-to-large amplitude maneuvering or for trim. Simulation evaluations have demonstrated that this approach provides adequate safety with a single-channel, independently monitored, fly-by-wire control system (ref. 22). There may be, of course, a controllability performance penalty associated with this approach, and a simulation was performed (ref. 23) using the VMS to evaluate the performance of the limited-authority system. The control system acceptability was evaluated with the shipboard transition and landing task (fig. 4) used in the experiments mentioned earlier.

\section{Research Aircraft Description}

The basic VSRA shown in figure 9 is the YAV-8B Harrier prototype, a single-seat, high-performance, transonic, light-attack, V/STOL aircraft. The aircraft is characterized by a shoulder-mounted supercritical swept wing and a swept stabilator, both with marked anhedral; a single vertical fin and rudder; under-fuselage lift-improvement devices; an improved inlet design; a double row of inlet doors; and four vectored-thrust nozzles, two on each side of the fuselage, with the forward pair incorporating a zero scarf to reduce exhaust splay.

A single Pegasus turbofan engine provides lift thrust for takeoff and landing, cruise thrust for conventional wing-borne flight, deflected thrust for V/STOL and in-flight maneuvering, and compressor bleed air for the aircraft's reaction control system. The nozzle system can direct the engine thrust from aft through vertical and to a reverse thrust position that directs the exhaust slightly forward.

Reaction control jets are used in hovering flight and conventional aerodynamic surfaces in wing-borne flight, with both systems contributing during transition. Hydraulically powered control-surface actuators are integrated with an electronically controlled, limited-authority stability augmentation system (SAS) that provides angular rate damping. Downward blowing front and rear pitch reaction-control valves and an allmovable stabilator provide longitudinal control. Reaction control system (RCS) valves, thrusting up and down at the wing tips and outboard ailerons, provide lateral control. Directional control is provided by a conventional unpowered rudder and by a left and right thrusting yaw RCS valve located in the tail cone.

\section{Flight Hardware and Software}

The VSRA control and display hardware and software is presented in schematic form in figure 10. The major additions to the YAV-8B include nozzle and throttle actuators, a primary flight-control digital computer, an independent monitor digital computer, a servo control unit (SCU), a new set of sensors required for the advanced flight-control laws, and a color, head-down display (HDD) incorporating a mode-menu capability. The SCU routes commands from the primary flight-control computer to the appropriate servos. A vital element in this single-channel system is the independent monitor computer, which checks the integrity of the flight-control computer hardware and software by comparing the actual aircraft closed-loop dynamics with the desired dynamics. A detailed description of this independent monitor is given in reference 22. All the items just mentioned, with the exception of the HDD, were simulated in the reference 22 and reference 23 experiments.

\section{Control System Servo Configuration}

Table I shows series- and parallel-actuator rates and authorities for the limited-authority system investigated in the simulation. The system employs limited-authority, high-rate series servos and large-authority 
(i.e., trim range), low-rate parallel servos for attitude (viz., the VSRA's SAS and trim servos); in addition, the VSRA's propulsion (throttle and nozzle) system was augmented by limited-authority high-rate series servos and full-authority, low-rate parallel servos. This series-parallel arrangement allowed for off-loading of the series servos by the parallel servos.

\section{Control Modes}

The control modes for the most advanced system evaluated in the earlier simulations (refs. 3-6) are listed in Table II. All control system modes used algorithms based on the State Rate Feedback Implicit Model Following (SRFIMF) concept discussed in reference 24. The SRFIMF achieves a broad class of response dynamics by using high-gain feedback of the commanded state and state rate. The dynamics chosen generally conform to those found to be optimum in previous simulation studies at Ames $($ refs. 17,18). An important feature of the SRFIMF is its self-trimming feature which ensures that external disturbances produce no steady-state error.

Control System Mechanization. - A brief description of the control inceptors (e.g., throttle thumbwheel, stick-grip thumbwheel, proportional thumb button, and stick) for the VSRA's advanced control modes follows. Figure 11 shows the inceptors and the corresponding elements on the HUD being controlled. A photograph of the interior (fig. 12) of the simulator cockpit shows the controls, HUD, instrument panel, and the continuous, three-window, computer-generated visual scene with an image of the Spruance-class destroyer. (The aircraft is positioned near the initial station-keeping point.)

Transition : The longitudinal acceleration-command/velocity-hold mode is controlled with the thumbwheel on the stick grip. The thumbwheel input from the pilot and longitudinal inertial velocity and acceleration are processed by the longitudinal control laws to provide the appropriate amount of engine-nozzle deflection to achieve the desired acceleration (or deceleration) and maintain the velocity present at the time the stick thumbwheel is placed in the detent position. Flightpath angle is commanded through the throttle lever thumbwheel. The thumbwheel input, inertial longitudinal velocity, vertical velocity, and acceleration are used by the flightpath control laws to generate the proper amount of engine fuel controller input to produce a change in thrust to achieve and maintain the commanded flightpath angle. The pilot is able to keep his left hand on the throttle because the parallel actuator follows up at the relatively slow rate of $2.8^{\circ} / \mathrm{sec}$ (Table I). Fore and aft movements of a thumb button on the stick command a fixed-pitch-rate-command/attitude-hold mode. Directional control laws process rudder pedal input, yaw rate and acceleration, and body-axis lateral acceleration at the center of percussion to provide a command to the yaw reaction control system (RCS) valve so as to give an aircraft-referenced lateral acceleration. Automatic turn coordination is also provided and is accomplished by providing a correct amount of yaw RCS valve opening based on airspeed and roll attitude and rate; no rudder pedal input is necessary.

Landing: Since the mechanical links between the stick and control surfaces are still intact, a proportional thumb button on the stick is required to control horizontal velocity. The stick itself cannot be used for this purpose since its inputs through the mechanical linkages would overpower the limited authority of the pitch and roll series-servos and adequate model-following would not occur. The longitudinal control laws generate a nozzle deflection command to achieve a desired longitudinal velocity by processing the pilot's longitudinal proportional thumb button input, as well as inertial longitudinal velocity and acceleration. A proper amount of RCS wing-tip valve opening is generated by the lateral control laws to achieve the desired lateral velocity though roll attitude. The fixed-pitch-rate-command/attitude-hold mode is commanded by a switch located on the throttle lever. The vertical-velocity-command/altitude-hold mode is controlled through the thumbwheel attached to the throttle lever. The nozzle lever, like the throttle lever, moves in response to the parallel servo. Yaw rate is commanded through pedals.

\section{Display}

The HUD format used throughout the simulation and which will be used for the VSRA evolved from work reported in references 3-6. Two distinct HUD formats are used: transition and hover. The symbols present during the transition and the hover/landing phases are shown in figures 13 and 14, respectively. 
These head-up displays provide the pilot with the guidance, command and situation information needed to perform the shipboard landing task in zero-zero visibility.

In transition (fig. 13), symbols represen ting a ghost aircraft and a longitudinal acceleration error contain the primary guidance information. The display is based on the principle of pursuit guidance (refs. 25,26$)$. The ghost aircraft identifies the position of a phantom aircraft located ahead of the real aircraft that performs the task perfectly. The pilot maneuvers his aircraft vertically and laterally to make the flightpath track the ghost aircraft. Deceleration is established by the pilot operating the appropriate controls to zero the acceleration-error ribbon. The length of this ribbon represents the error between the aircraft's deceleration and the constant deceleration that brings the aircraft to a hover at a predetermined initial-station keeping point. A piecewise-constant, two-step (nominally $0.1 \mathrm{~g}$, stepping to $0.05 \mathrm{~g}$ when $1000 \mathrm{ft}$ away from the ship) deceleration was chosen to be the guidance command provided to the pilot and was based on previous transition task simulations conducted at Ames. Situation information that accompanies the flightpath and ghost aircraft symbols include aircraft attitude, speed, altitude, engine percent rpm, thrust vector angle, longitudinal acceleration, heading, and distance to the initial station-keeping point.

The hover display format (fig. 14) is a superposition of vertical and horizontal (plan view) aspects. The central element is a fixed "trident" symbol that represents a plan view showing the correct relative locations of the landing gear and nose boom. The landing pad is presented in both horizontal and vertical aspects. In the horizontal aspect, the pad symbol is geometrically similar to the Spruance-class destroyer pad and is scaled in both size and relative position to match the trident. In the vertical aspect, the pad (deck bar) is shown "edge on" at a distance below the trident that is proportional to the altitude above the deck. The primary guidance information in hover is contained in symbols representing the desired hover point, height above the deck (deck bar), and vertical velocity allowable within a prescribed landing gear limit. In operation, the pilot, using the appropriate controls, moves a commanded-horizontal-velocity symbol to the desired hover point and holds it there while maintaining a rate of descent close to zero, as shown by a commanded-vertical-velocity symbol. When the aircraft is at the desired hover point, the pilot establishes a vertical descent rate, within the limits of the allowable-vertical-velocity ribbon, until touchdown. The allowable-vertical-velocity ribbon is especially useful when the ship deck is heaving because it includes the velocity of the deck as well as that of the aircraft. Attitude, airspeed, velocity of airplane with respect to ship, engine percent rpm, thrust-vector angle, heading, hangar door position, and wind direction are provided as situation information.

\section{Simulation Results}

Pilot comments and ratings for the limited-authority control system implementation of the advanced control system were obtained. The pilot ratings were based on the Cooper-Harper Handling Qualities Rating Scale (ref. 2). Three Ames Research Center test pilots participated in the simulation. The pilot most experienced in Harriers was extensively involved in the control and display development process for previous V/STOL simulation efforts at Ames in both engineering and test pilot roles. Another pilot was involved in the development of flightpath symbol and control schemes for short takeoff and landing (STOL) aircraft before becoming involved with V/STOL simulation and flight test evaluations of the Harrier. The third pilot has been active in the development of flightpath symbology and control concepts for conventional takeoff and landing (CTOL) and STOL aircraft as both a research engineer and test pilot; he has no Harrier flight time but has participated in previous V/STOL simulations.

The experimental variables evaluated by the pilots included the two tasks (shipboard transition and landing) and the three environmental conditions for the shipboard transition and landing tasks (root-meansquare (rms) turbulence levels of 0,3 , and $6 \mathrm{ft} / \mathrm{sec}$, and sea states 0,4 , and 6 , respectively).

Transition and Landing. - The variation of pilot ratings with turbulence levels for the flightpath/acceleration-command system for the transition task is shown in fig. 15a. Uncoupled flightpath and acceleration-command modes, along with a clear indication of guidance errors on the HUD contributed to the generally desirable flying qualities achieved. A degradation in flying qualities is evident as the turbulence level is increased - the average pilot rating worsens from marginal Level 1 to Level 2 as atmospheric turbulence increases from 0 to $6 \mathrm{ft} / \mathrm{sec} \mathrm{rms}$. Most of the pilots' criticisms were directed at the uncommanded movement of the stick in the pilot's hand (caused by the action of the parallel servos). In general, the low 
rates at which the parallel servos off-loaded the series servos caused a detectable degradation in the control modes, particularly in pitch and flightpath response.

The variation in pilot ratings for the landing task in sea states 0,4 , and 6 is shown in figure $15 \mathrm{~b}$. Level 1 flying qualities in sea states as high as 4 and Level 2 flying qualities in sea state 6 were achieved by the limited-authority translational rate command system. As noted above, parallel-servo-induced stick movements were noticeable to the pilot and tended to interfere slightly with the precision with which the pilot could command horizontal velocity (through the stick-grip-mounted proportional thumb button). There does not appear to be much change in the average pilot rating in sea states 0 and 4 , largely because the pilot technique was basically the same for both sea states. In these sea states, ship motion was relatively mild, and there was rarely any need to correct the descent rate to compensate for deck heave. However, in sea state 6 , the ship motion was severe enough to require arresting the descent rate and even required a rapid increase in altitude to avoid gear damage by the rapidly rising deck. The work load associated with continuously varying vertical velocity during the descent contributed to the significant increase in pilot ratings and resulted in Level 2 flying qualities.

VSRA Control System Acceptability. - The results, in terms of pilot ratings obtained for the decelerating approach and landing tasks, indicate that the limited-authority control system to be implemented in the VSRA will be an acceptable alternative to a full-authority control system. The pilot ratings for the transition task obtained for the limited-authority system (fig. 15a) in $3 \mathrm{ft} / \mathrm{sec} \mathrm{rms}$ (i.e., moderate) turbulence fall within the pilot rating band of the "FLIGHTPATH-ACCEL/DECEL COMMAND" ratings (evaluated using a full-authority control system) of figure 7 . Similarly, for the landing task, the pilot ratings obtained for the limited-authority translational rate command system (fig. 15b), with varying levels of sea state, fall close to or within the "VELOCITY COMMAND" pilot rating band of the "SMALL SHIP" (i.e., Spruance-class destroyer) data obtained assuming a full-authority control system.

\section{FLIGHT RESEARCH PROGRAM}

The flight research program is being conducted in two phases which are based upon the appropriate modifications of the aircraft required to facilitate the flight research. The first phase requires modifying the aircraft to install a complete data acquisition system and the sensors necessary for measuring aerodynamic, control, propulsion, and inertial parameters. The second phase requires modifications necessary to install the VSRA research system described previously.

Phase I

The first phase flight experiments are aimed at documenting basic aircraft propulsion, reaction control, and aerodynamic effects in the V/STOL regime, through the use of parameter identification techniques, for the purpose of validating the aircraft simulation math model and establishing control design criteria for advanced STOVL aircraft. Flying qualities tasks have been conducted to validate the simulator math model of the aircraft and to identify visual and motion cues used by the pilot to control a hovering jet V/STOL aircraft. Following the initial research flights, a spare engine, modified to include bleed flow instrumentation, will be installed in the aircraft and a fight test will be conducted to measure bleed-flow usage under various flight conditions.

Simulation Fidelity Experiment. - A specific Aying qualities task that could be flown in both the simulator and in flight was required to check simulation fidelity. The test rig used for this comparison between flight and simulation is composed of a pair of optical sights that can be arranged either vertically or horizontally. The sights provide an indication to the pilot of his location in three-dimensional space. The aircraft is shown hovering against the test rig in both the vertical and horizontal configurations in figure 16. A viewing point external to the aircraft's computer generated image was used to produce the simulation scene.

A close-up of one of the targets is shown in figure 17. A pair of "rabbit ears" extend from the target's backing plate that allow the pilot to use parallax to position himself at the ideal hover point $(66 \mathrm{ft}$ behind the center of the target). When the pilot's eyepoint is at the ideal hover point, the ends of the extending 
"rabbit ears" appear to align vertically with the inner edges of the target's four black corner squares. The resolutions of positional deviations from the ideal hover point are less than approximately $1.5 \mathrm{ft}$ both laterally and vertically while being five times less sensitive longitudinally.

The task for both simulation and flight consisted of the pilots flying (with SAS on) three cycles between the targets while stabilizing at the ideal hover point in front of each hover target during the cycles. CooperHarper pilot ratings (ref. 2) for both tasks in simulation and flight are shown for three pilots in figure 18. The ratings illustrate that the task is in the Level 2 boundaries (adequate) for both simulation and flight.

In addition to the pilot's handling qualities evaluations, task performance was also measured for simulation and flight. Figure 19 shows the aircraft's position while performing both the horizontal and vertical tasks. Errors from the left target for the horizontal task and from the top target for the vertical task are plotted. This figure illustrates that the pilot's positioning performance for both tasks in simulation and flight is similar.

Pilot comments reveal that the aircraft characteristics with SAS on and demands on the pilot were about the same in flight as in the motion-base simulation. All pilots felt that the lateral sensitivity in the simulation was lower than in flight. The pilots also felt that the task was harder to perform in the simulation, and this is evident by the slight degradation in their pilot ratings. From this evaluation, one can conclude that for flying qualities and controllability purposes, the simulation with motion is a satisfactory representation of the aircraft in hover.

Bleed Flow Experiment. - In an effort to provide design criteria for supersonic STOVL aircraft reaction control power requirements, a spare engine, modified to include bleed flow instrumentation, will be installed in the aircraft and a flight test will be conducted to measure bleed-flow usage under various flight conditions. At this time, little is known about the amount of bleed flow drawn from the compressor or the amount of control thrust actually provided at the reaction control valves, except that it is adequate for the Harrier's flight regimes. Accurate measurement of these quantities is necessary to validate and improve the simulation, to document the bleed requirements of various advanced flight control systems, and to extrapolate to the bleed requirements for future STOVL aircraft. Parameter identification techniques will be used to improve the model of the reaction control system and estimate system losses in the ducting and at the reaction control valves.

\section{Phase II}

The second phase of the flight program begins after the aircraft has been modified for the integrated flight propulsion control system research. As discussed in the previous section, two digital flight computers and a programmable symbol generator for the HUD will be installed and integrated with the existing HUD and navigation sensors. A ground-based integration and test facility which simulates the aircraft and its flight environment will be used to develop the flight computer software and validate the research system functions prior to flight. Results from the Phase I flight experiments will be used to upgrade the aircraft simulation model in the facility.

During Phase II, evaluations of integrated flight and propulsion control models, HUD formats, and guidance concepts will be conducted during takeof, transition, hover, and landing operations under visual and simulated instrument meteorological conditions. The aircraft will be flown along a final approach trajectory similar to that shown in figure 4 to duplicate the shipboard landing task. Complete approaches from conversion (160 knots) to touchdown will be flown using precisely defined approach paths and precisely defined hover and touchdown points. These approaches will be flown in a variety of wind conditions with and without the use of the HUD to determine the sensitivity of handling qualities and task precision to turbulence. The HUD will be used to supply the necessary guidance information.

Initially all flight research will be conducted at a conventional landing field. As the research system is perfected and confidence in its reliability improves, approaches will be flown to small ships at sea. Pilot subjective assessment and measurements of task precision and control authority requirements will be made. Results will be used to define methods to improve current adverse weather operational capability, establish operational procedures for use of the advanced systems, and substantiate tentative design criteria obtained from analytical studies and simulation experiments. 
The flight research will also include a parametric study of a variety of pilot control modes ranging from simple attitude rate command to horizontal translational rate command through pitch and roll. Additionally, the damping of the aircraft in the vertical degree of freedom will be augmented by modulating engine thrust. This vertical augmentation will be variable to provide a wide range of effective vertical damping. A simplified integrated power management concept using a throttle-mounted thumbwheel switch to command nozzle movement will be implemented and evaluated as part of the experiment.

\section{CONCLUDING REMARKS}

This paper has reviewed results of several Ames Research Center simulation investigations of fixedwing V/STOL aircraft performing decelerating approaches under instrument flight conditions, followed by recovery to confined landing pads or aboard ship and has described flight experiments to be conducted on the NASA VSRA to substantiate the simulation results. From the simulation programs, contributions of control augmentation and integrated electronic displays to the operation of these aircraft in adverse weather and aboard ship have been defined. In particular, for the demanding task of a decelerating approach to hover on instruments, aircraft with vectored thrust capability may require some form of decoupled flightpath and longitudinal acceleration command in addition to attitude command to achieve satisfactory flying qualities. Further, a cockpit display that integrates situation and command information such as some of the recently developed flightpath-centered presentations are essential to the successful performance of these operations. For the vertical landing under demanding conditions such as recovery to a small ship over a range of weather conditions, a velocity command system is required to achieve satisfactory flying qualities. Operations from larger ships or from austere land-based sites can be accomplished satisfactorily with attitude or, in some cases, with rate command systems, as simulation and Harrier flight experience in the United States and the United Kingdom have shown.

With these simulation results as a basis, a program has been defined to modify the VSRA so as to be able to conduct experiments to evaluate these control augmentation and display concepts in flight. First, a motion-base simulation was performed to evaluate the acceptability of a limited-authority control system for the VSRA that has the potential to create a research capability for in-flight evaluation of advanced V/STOL control and display systems as well as the ability to validate the results of previous simulation investigations. The results of this simulation showed that the limited-authority control system will provide an acceptably capable system within budgetary constraints.

The flight research program is being conducted in two phases: the first phase is concentrating on developing a data base on the aircraft and the second phase will include development and evaluation of the integrated control and display concepts for the terminal area flight regime. A Phase 1 experiment has been conducted that assessed the YAV-8B simulation fidelity in hover by use of a precision hover task. Pilot ratings, pilot comments, and task performance measures established correspondence of the the simulated and actual YAV-8B in hover. During the Phase II flight program, evaluations of integrated flight and propulsion control modes, HUD formats, and guidance concepts will be conducted during takeoff, transition, hover, and landing operations under visual and simulated instrument meteorological conditions. Pilot subjective assessment and measurements of task precision and control authority requirements will be made. Results will be used to define methods to improve current adverse weather operational capability, establish operational procedures for use of the advanced systems, and substantiate tentative design criteria obtained from analytical studies and simulation experiments. 


\section{REFERENCES}

1. Anon.: Displays for Approach and Landing of V/STOL Aircraft. AGARD Advisory Report 51, November 1972.

2. Cooper, G. E. and Harper, R. P., Jr.: The Use of Pilot Ratings in the Evaluation of Aircraft Handling Qualities. NASA TN D-5153, 1969.

3. Farris, G. G.; Merrick, V. K.; and Gerdes, R. M.: Simulation Evaluation of Flight Controls and Display Concepts for VTOL Shipboard Operations. AIAA Paper 83-2173, 1983. 1983.

4. Merrick, V. K. and Gerdes, R. M.: VTOL Controls for Shipboard Operations. SAE Paper 831428,

5. Merrick, V. K.: Simulation Study of Two VTOL Control/Display Systems in IMC Approach and Landing. NASA TM 81295, 1981.

6. Merrick, V. K.: Simulation Study of Two VTOL Control/Display Systems in IMC Approach and Shipboard Landing. NASA TM 85996, 1984.

7. Lebacqz, J. V.; Merrick, V. K.; and Franklin, J. A.: Control and Display Requirements for Decelerating Approach and Landing of Fixed- and Rotary-Wing VSTOL Aircraft. AHS Paper A-86-42-70-100, May 1986.

8. Stapleford, R. L.; Clement, W. F.; Heffley, R. K.; Booth, G. .C.; and Fortenbaugh, R. L.: Flight Control/Flying Qualities Investigation for Lift/Cruise Fan V/STOL. NADC Report 77143-30, August 1979.

9. Aiken, E. W.; Hilbert K. B.; Landis, K. H.; and Glusman, S. I.: An Investigation of Side-Stick Controller/Stability and Control Augmentation System Requirements for Helicopter Terrain Flight Under Reduced Visibility Conditions. AIAA Paper 84-0235, January 1984.

10. Lebacqz, J. V. and Aiken, E. W.: A Flight Investigation of Control, Display, and Guidance Requirements for Decelerating Descending VTOL Instrument Transitions Using the X-22A Variable Stability Aircraft, Volume I: Technical Discussion and Results. Calspan Report AK-5336-F-1, September 1975.

11. Lebacqz, J. V.; Radford, R. C.; and Beilman, J. L.: An Experimental Investigation and ControlDisplay Requirements for Jet-Lift VTOL Aircraft in the Terminal Area. NADC-76099-60, July 1978.

12. Kelly, J. R.; Niessen, F. R.; Thibodeaux, J. J.; Yenni, K. R.; and Garren, J. F., Jr.: Flight Investigation of Manual and Automatic VTOL Decelerating Instrument Approaches and Landings. NASA TN D-7524, July 1974.

13. Niessen, F. R.; Kelly, J. R.; Garren J. F., Jr.; Yenni, K. R.; and Person, L. H.: The Effect of Variations in Controls and Displays on Helicopter Instrument Approach Capability. NASA TN D-8385, 1977.

14. Aiken, E. W. and Merrill, R. K.: Results of a Simulator Investigation of Control System and Display Variations for an Attack Helicopter Mission. AHS Paper 80-28, May 1980.

15. Brigadier, W. L.: Analysis of Control Actuator Authority Requirements for Attitude and Translational Rate Command Augmentation Systems for the XV-15 Tilt Rotor Research Aircraft. NASA TM 81243 and AVRADCOM TR-80-A-13, December 1980.

16. Johns, J. B. and Donley, S. T.: Results of Phase 1 V-22 Piloted Simulation. NADC Report 85117-60, September 1985. 
17. Greif, R. K.; Fry, E. B.; Gerdes, R. M.; and Gossett, T. D.: Effect of Stabilization on VTOL Aircraft in Hovering Flight. NASA TN D-6900, 1972.

18. Corliss, L. D. and Dugan, D. C.: A VTOL Translational Rate Control Systems Study on a Six Degree of Freedom Motion Simulator. NASA TM X-62,194, 1972

19. Rolls, L. S. and Drinkwater, F. J. III: A Flight Investigation of the Attitude Control Power and Damping Requirements for a Visual Hovering Task in the Variable Stability and Control X-14A Research Vehicle. NASA TN D-1328, 1962.

20. Radford, R. C. and Andrisani, D. III: An Experimental Investigation of VTOL Flying Qualities Requirements in Shipboard Landings. AIA A Paper 80-1625, August 1980.

21. Davis, J.; Garnett, T.; and Gaul, J.: Heavy Lift Helicopter Flight Control System. Vol. III: Automatic Flight Control System Development and Feasibility Demonstration. USAAMRDL-TR-77-40C, September 1977.

22. Schroeder, J. A.; Moralez, E.; and Merrick, V. K.: Simulation Evaluation of the Control System Command Monitoring Concept for the NASA V/STOL Research Aircraft (VSRA). AIAA Paper 87-2255-CP, 1987.

23. Moralez, E. III; Merrick, V. K.; and Schroeder, J. A.: Simulation Evaluation of the Advanced Control Concept for the NASA V/STOL Research Aircraft (VSRA). AlAA Paper 87-2535-CP, 1987.

24. Merrick, V. K.: Study of the Application of an Implicit Model Following Flight Controller to Lift-Fan VTOL Aircraft. NASA TP 1040, 1977.

25. Bray, R. S. and Scott, B. C.: A Head-Up Display for Low Visibility Approach and Landing. AIAA Paper 81-0130, 1981.

26. Franklin, J. A. and Hynes, C. S.: Flight Evaluation of Highly Augmented Controls and Electronics Displays for Precision Approach and Landing of Powered-Lift Aircraft. AIAA Paper 85-1944, 1985. 
Table I. - VSRA control system servos

\begin{tabular}{|c|c|c|c|c|c|}
\hline \multirow{3}{*}{$\begin{array}{c}\text { FORCE \& MOMENT } \\
\text { PRODUCER }\end{array}$} & \multicolumn{4}{|c|}{ ACTUATOR AUTHORITIES AND RATES } & \multirow{3}{*}{$\begin{array}{c}\begin{array}{c}\text { FULL } \\
\text { CONTROL } \\
\text { TRAVEL }\end{array} \\
12.7^{\circ},-11.7^{\circ}\end{array}$} \\
\hline & \multicolumn{2}{|c|}{ SERIES } & \multicolumn{2}{|c|}{ PARALLEL } & \\
\hline & $+1.5^{\circ},-1.5^{\circ}$ & $60^{\circ} / \mathrm{sec}$ & $+7.5^{\circ},-4^{\circ}$ & $2.2^{\circ} / \mathrm{sec}$ & \\
\hline PITCH ACS FWD & $+29 \%,-29 \%$ & $346 \% / \mathrm{sec}$ & $100 \%, 0 \%$ & $29 \% / \mathrm{sec}$ & 7.3 in. $^{2}, 0$ in. $^{2}$ \\
\hline PITCH RCS AFT & $+19 \%,-19 \%$ & $750 \% / \mathrm{sec}$ & $69 \%, 0 \%$ & $27 \% / \mathrm{sec}$ & 8.7 in. $^{2}, 0$ in. $^{2}$ \\
\hline AILERONS & $+2.0^{\circ},-2.0^{\circ}$ & $80^{\circ} / \mathrm{sec}$ & $+4.0^{\circ},-6.0^{\circ}$ & $2.0^{\circ} / \mathrm{sec}$ & $+12^{\circ},-27^{\circ}$ \\
\hline ROLL RCS & $+16 \%,-16 \%$ & $760 \% / \mathrm{sec}$ & $54 \%,-54 \%$ & $9.6 \% / \mathrm{sec}$ & +8.1 in. $^{2},-8.1$ in. $^{2}$ \\
\hline RUDDER & - & - & - & - & $+15^{\circ},-15^{\circ}$ \\
\hline YAW RCS & $+50 \%,-50 \%$ & $500 \% / \mathrm{sec}$ & - & - & +3.5 in. $^{2},-3.5$ in. $^{2}$ \\
\hline THRUST (PSA) & $+5^{\circ},-5^{\circ}$ & $100^{\circ} / \mathrm{sec}$ & $75^{\circ}, 0^{\circ}$ & $2.8^{\circ} / \mathrm{sec}$ & $75^{\circ}, 0^{\circ}$ \\
\hline NOZZLES & $+5^{\circ},-5^{\circ}$ & $90^{\circ} / \mathrm{sec}$ & $98.5^{\circ}, 2^{\circ}$ & $4.8^{\circ} / \mathrm{sec}$ & $98.5^{\circ}, 2^{\circ}$ \\
\hline
\end{tabular}

RCS-REACTION CONTROL SYSTEM

PSA.POWER SPINDLE ANGLE (SAME AS THROTTLE LEVER ANGLE)

Table II. - VSRA command modes

\begin{tabular}{|c|c|c|}
\hline \multirow[t]{2}{*}{ AXIS } & \multicolumn{2}{|c|}{ MODE } \\
\hline & TRANSITION & HOVER \\
\hline PITCH & $\mathrm{RC} / \mathrm{AH}$ & $\mathrm{RC} / \mathrm{AH}$ \\
\hline ROLL & RC/AH & vc \\
\hline YAW & $A C / T C$ & RC \\
\hline VERTICAL & FPC & VC/ALT HOLD \\
\hline \multirow[t]{6}{*}{ LONGITUDINAL } & $\mathrm{AC} / \mathrm{VH}$ & vc \\
\hline & COMMAND & STABILIZATION \\
\hline & RC: Rate Command & AH: Attitude Hold \\
\hline & $\begin{aligned} & \text { AC: } \text { Acceleration } \\
& \text { Command }\end{aligned}$ & $\begin{array}{l}\text { TC: Turn } \\
\text { Coordination }\end{array}$ \\
\hline & $\begin{aligned} \text { FPC: Flightpath } \\
\text { Command }\end{aligned}$ & VH: Velocity Hold \\
\hline & $\begin{aligned} \text { VC: Velocity } \\
\text { Command }\end{aligned}$ & \\
\hline
\end{tabular}



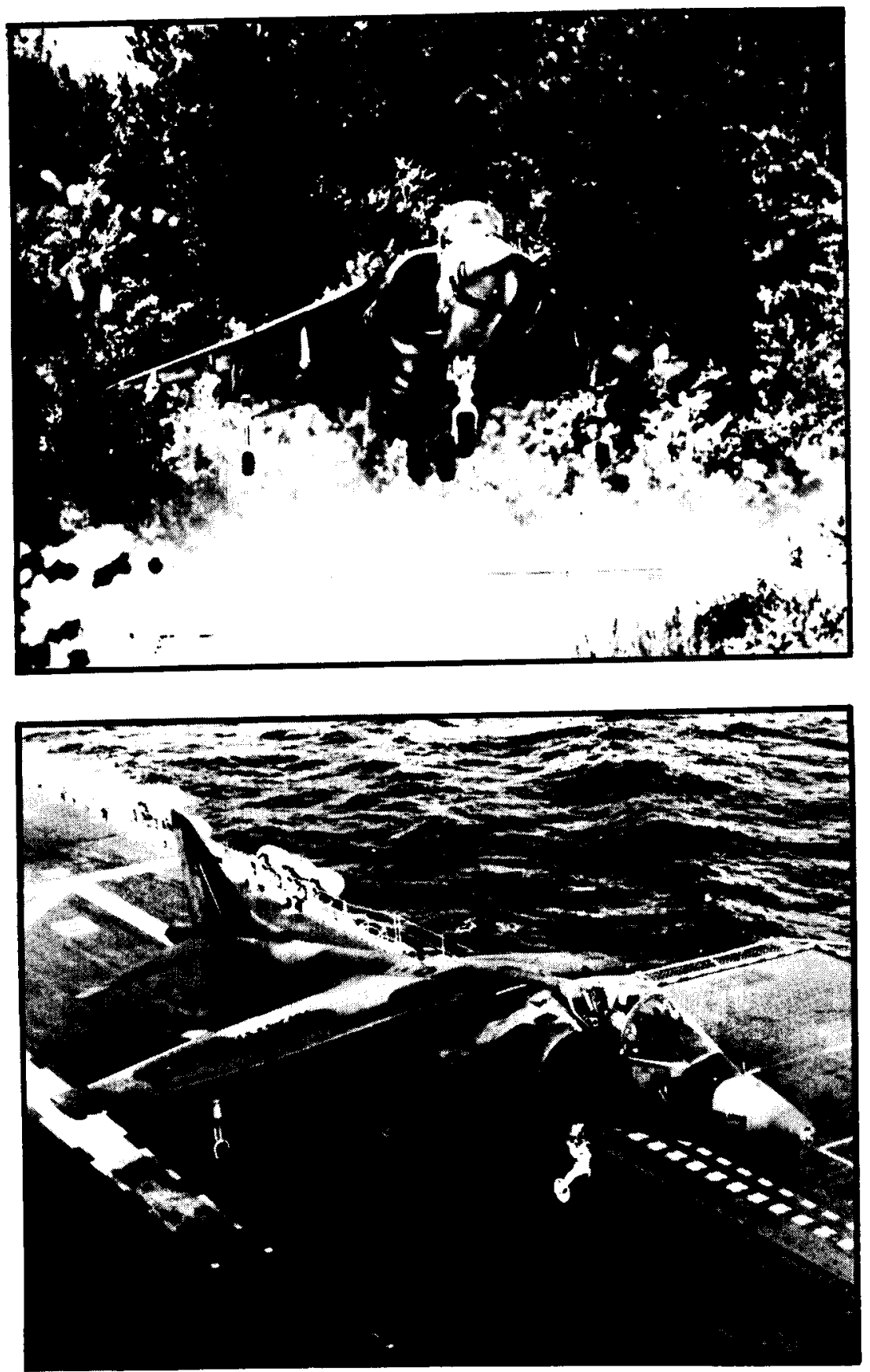

Figure 1. - AV-8B Harrier operations at austere sights and aboard ship (photos courtesy of McDonnel-Douglas and U.S. Navy and Marines). 

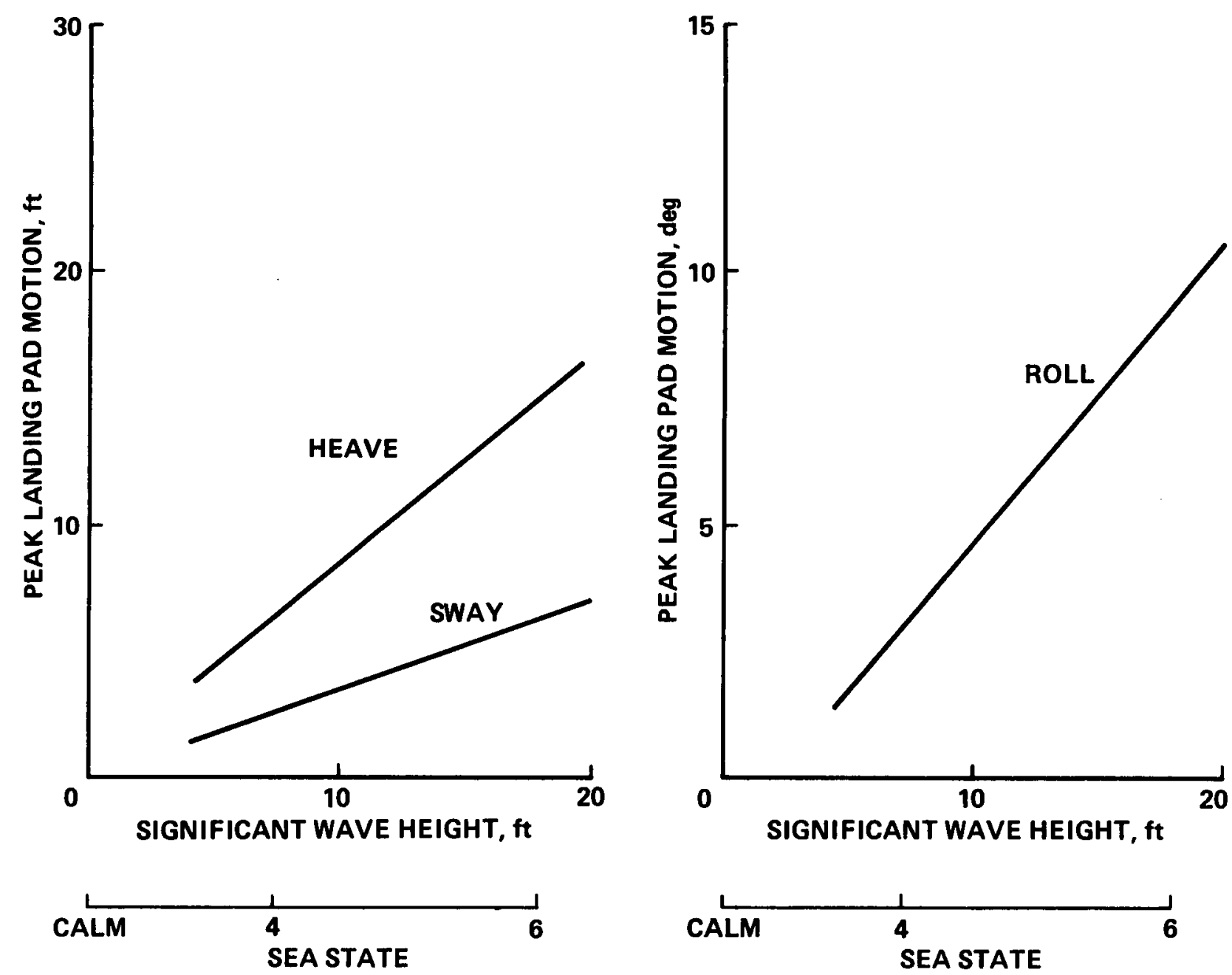

Figure 2. - Landing pad motion characteristics for destroyer. 

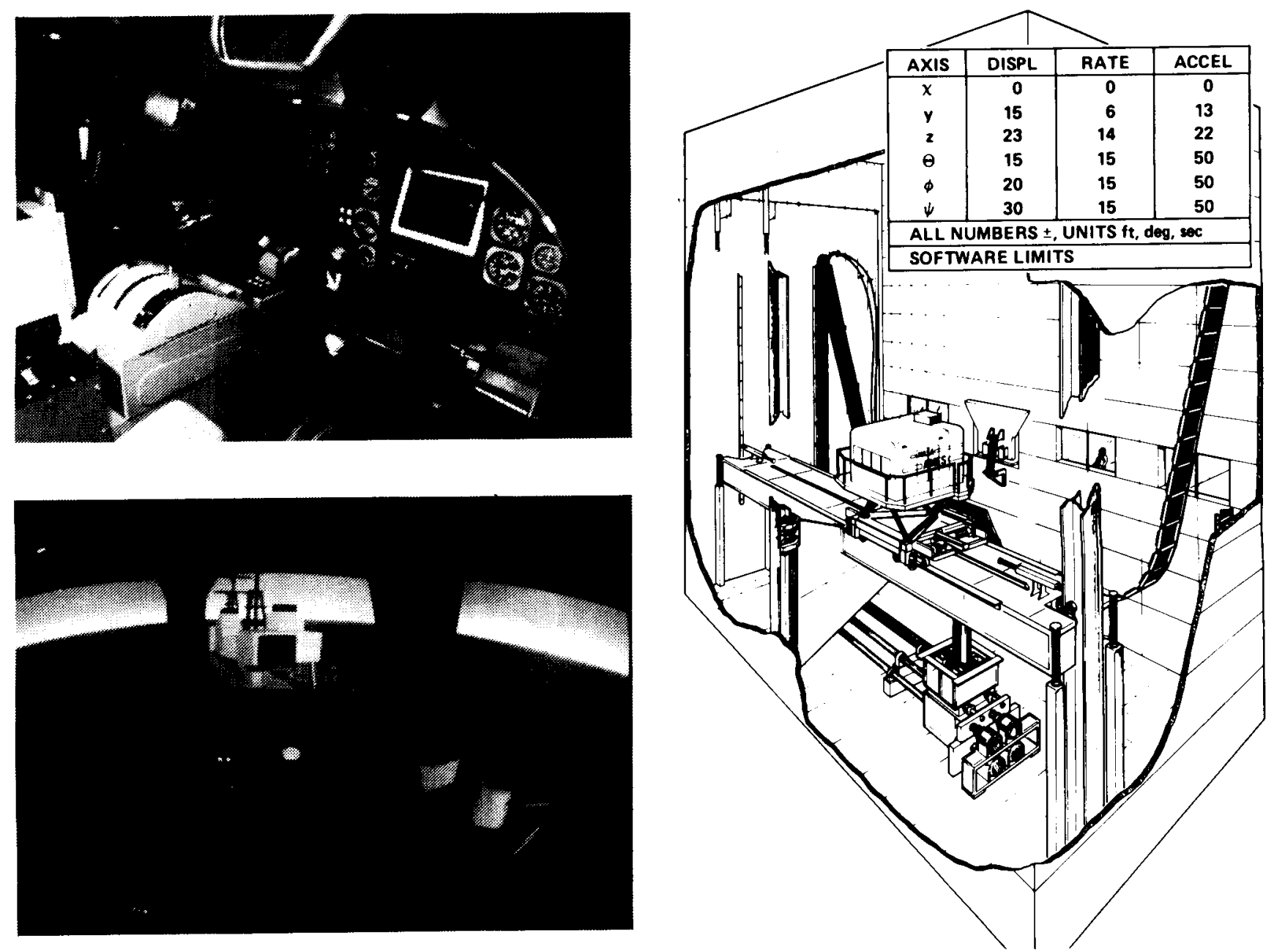

Figure 3. - NASA Ames Research Center's Vertical Motion Simulator (VMS).

ORIGINAL PAGE IS OF POOR QUALITY. 


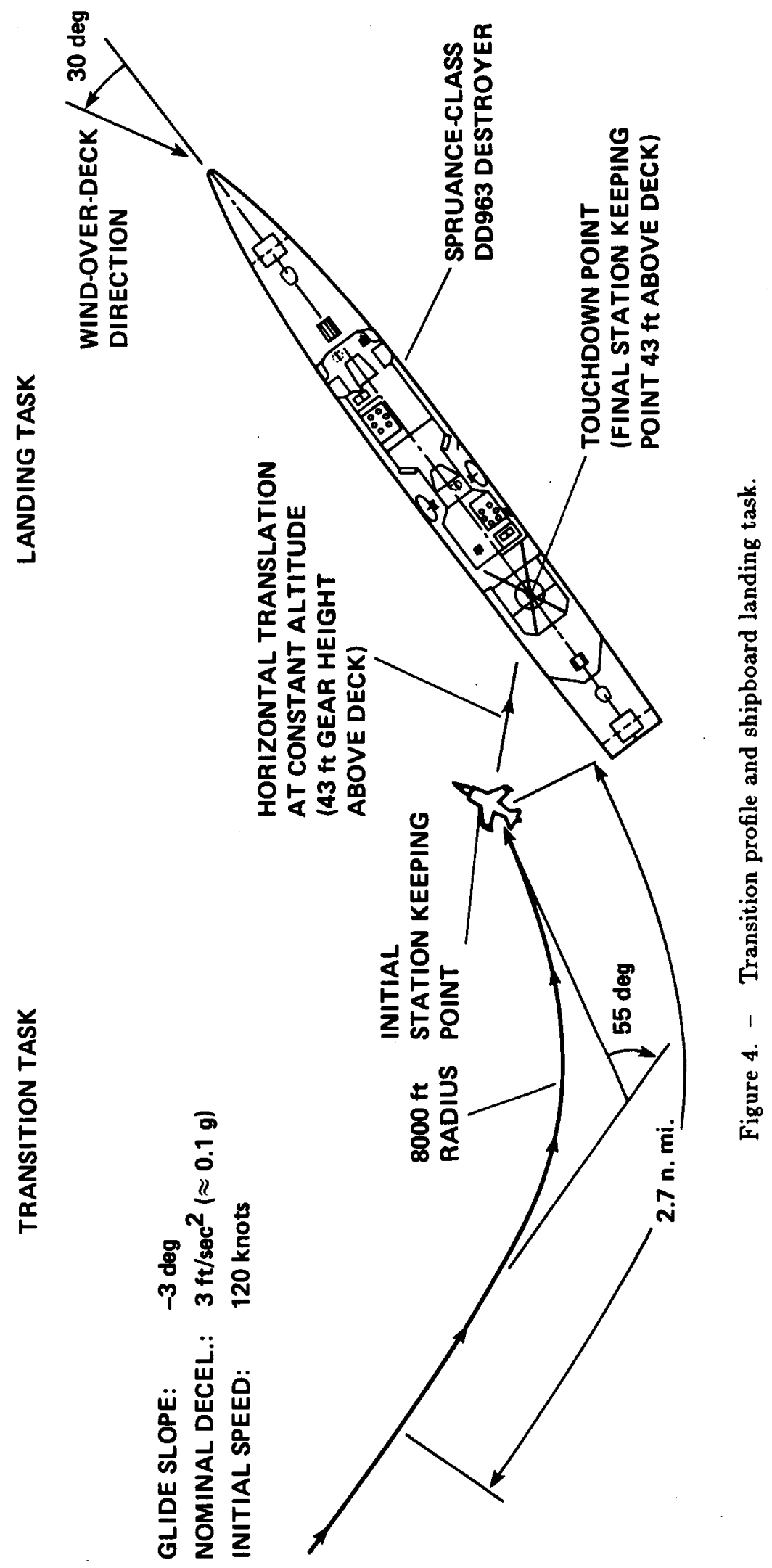




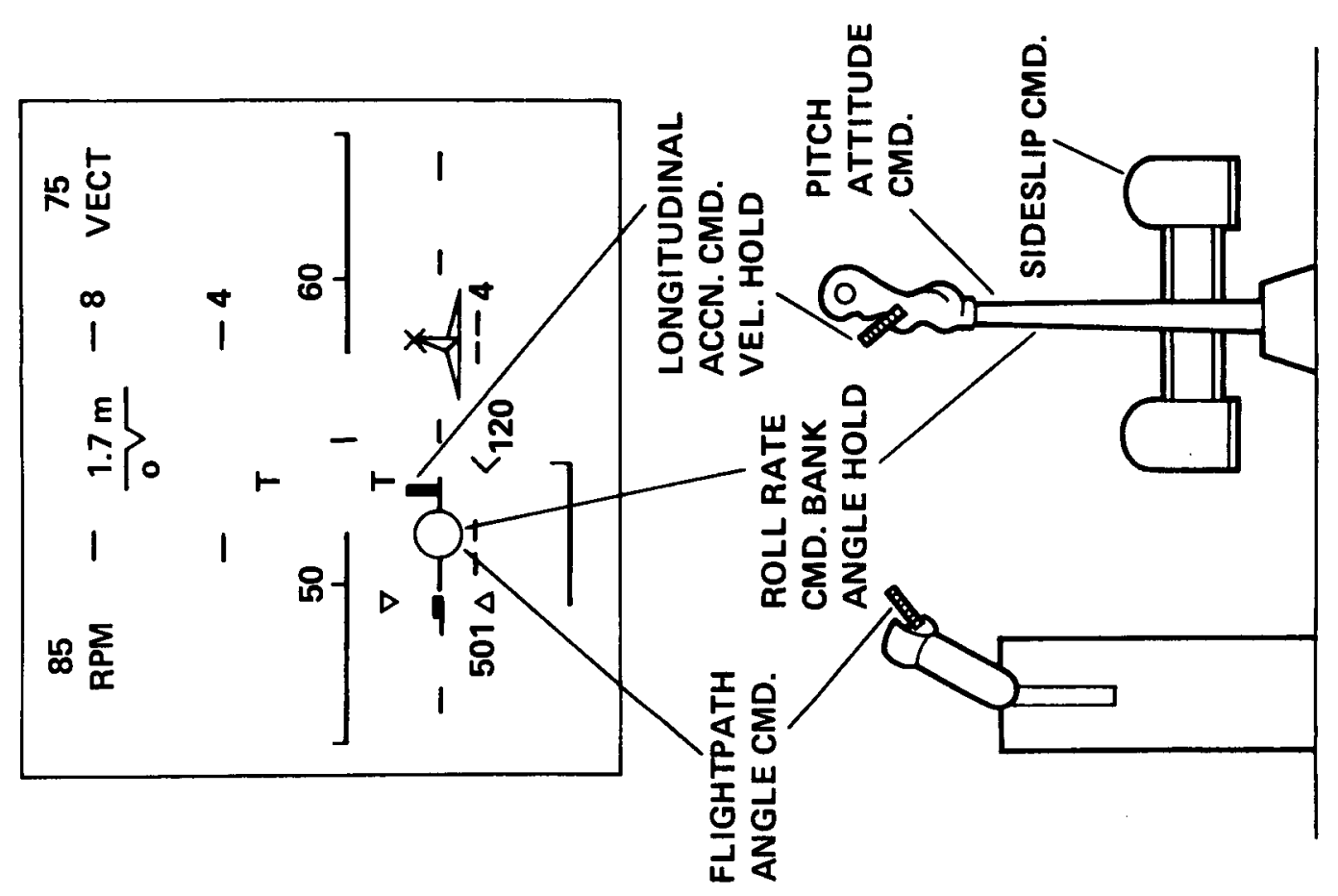

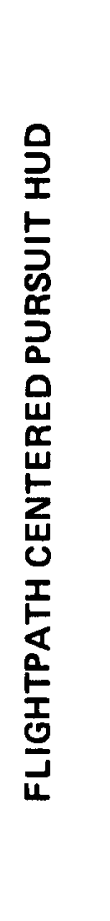

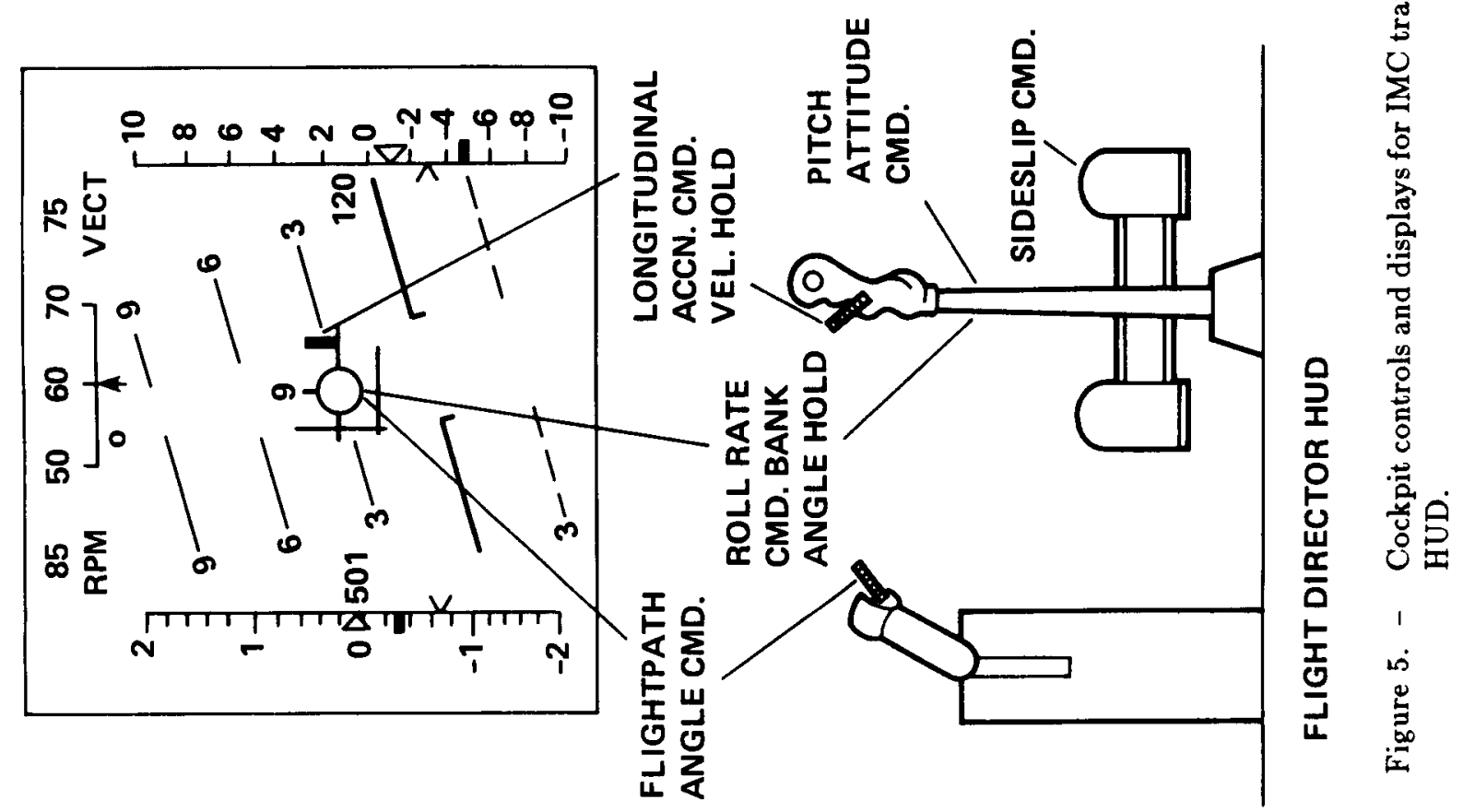




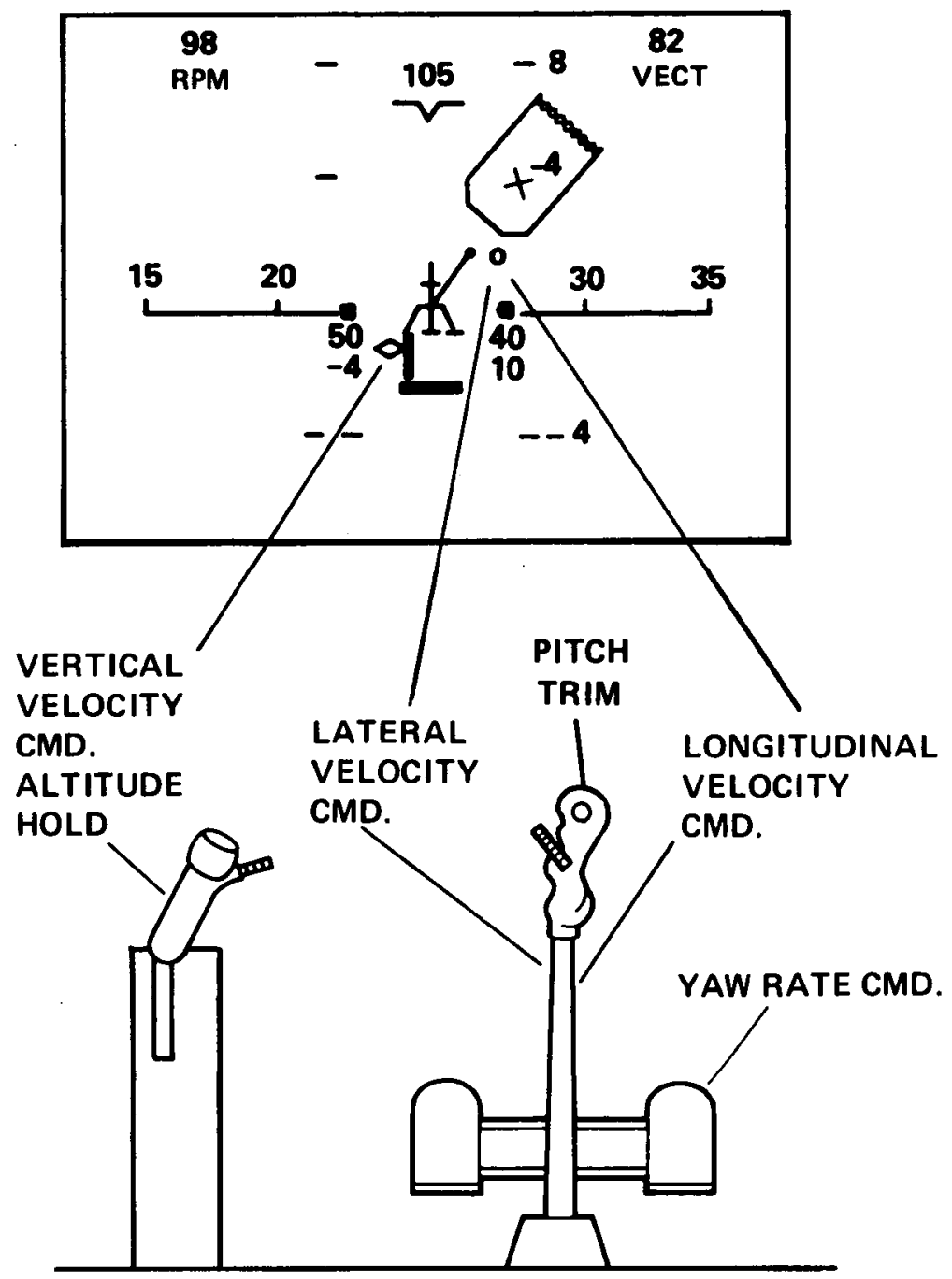

Figure 6. - Cockpit controls and displays for IMC hover. 


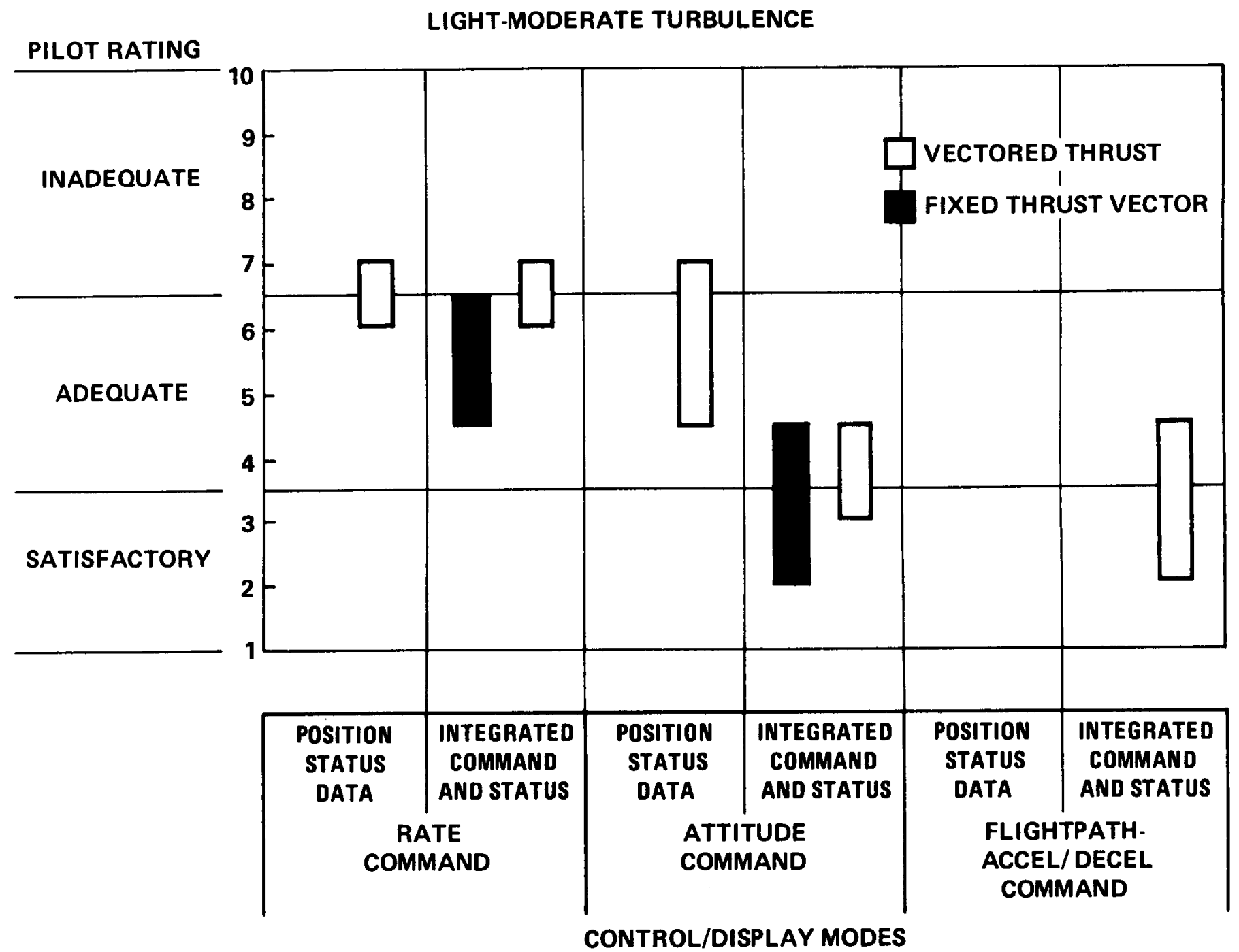

Figure 7. - Influences on instrument decelerating approach. 


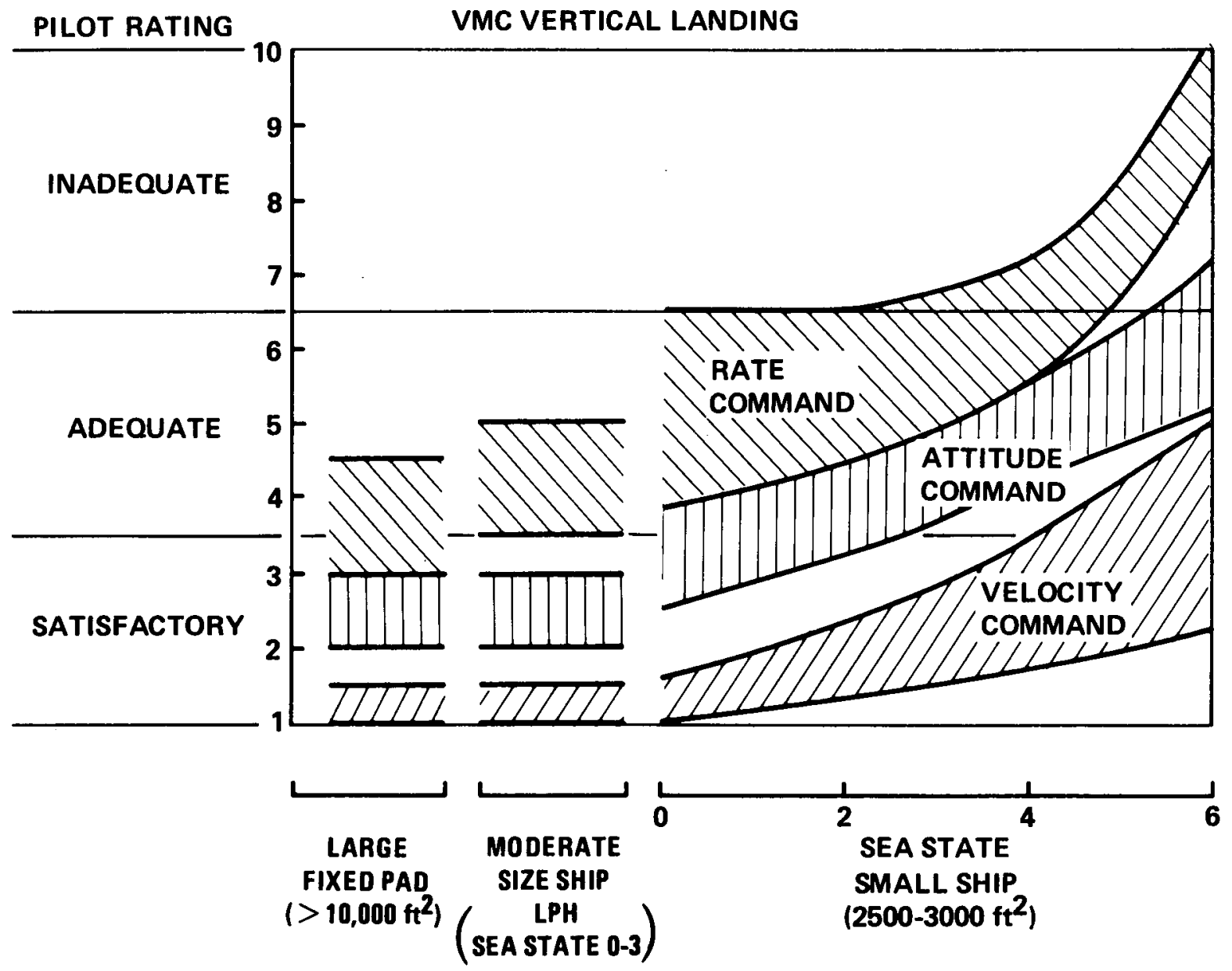

Figure 8. - Infiuences on vertical landing. 


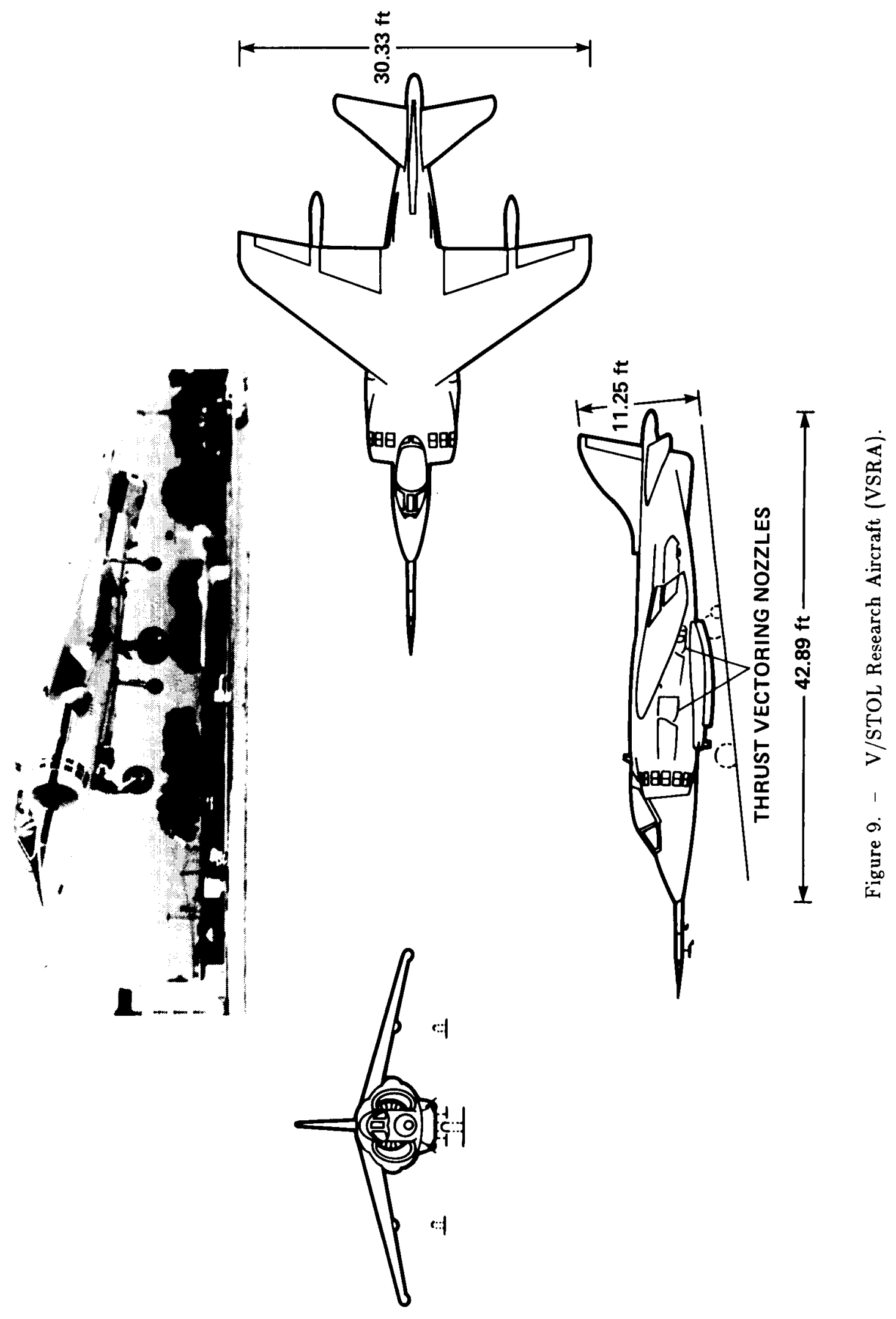

ORIGINAL PAGE IS OE POOR QUALITY. 


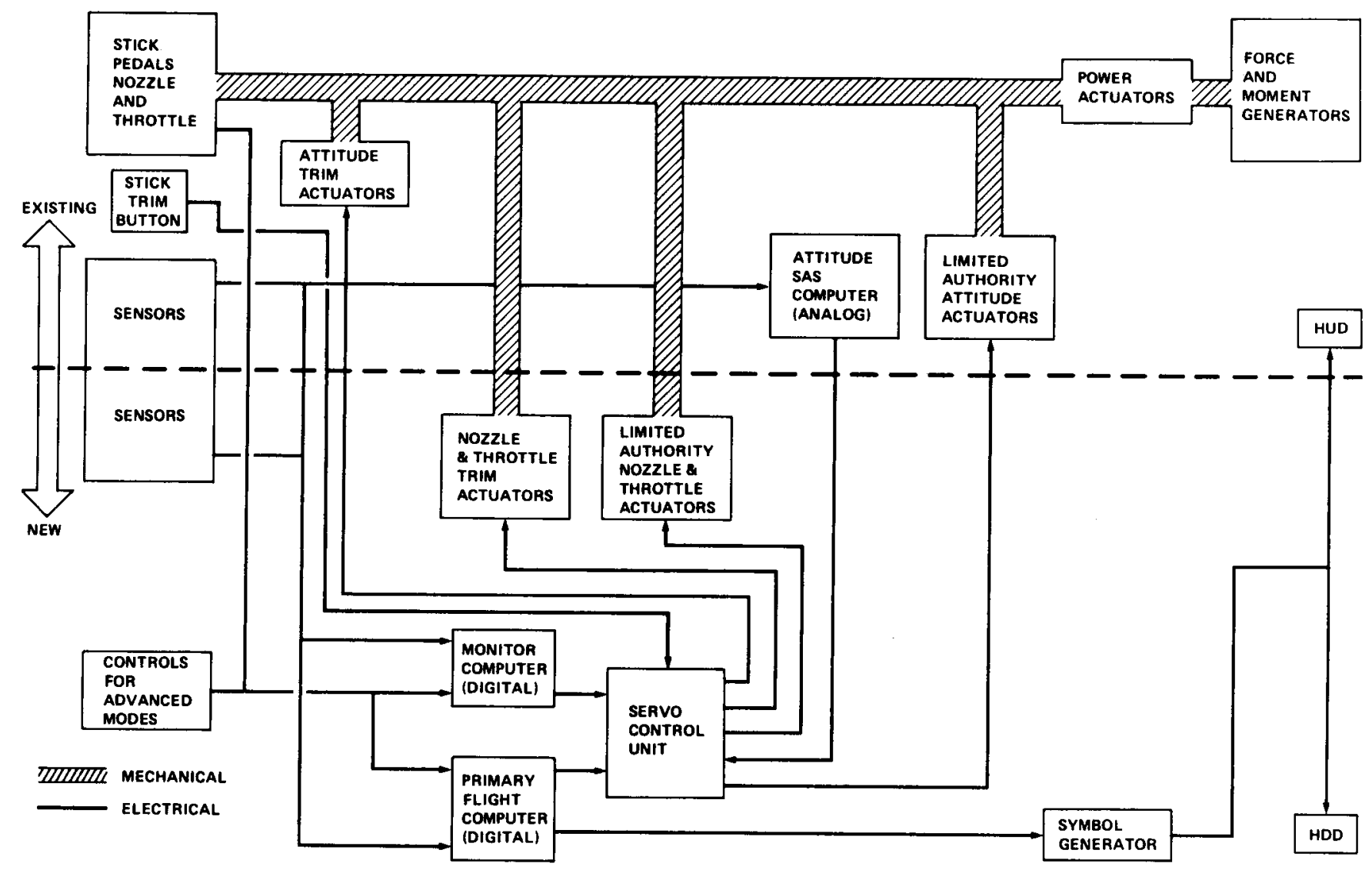

Figure 10. - VSRA control/display system. 


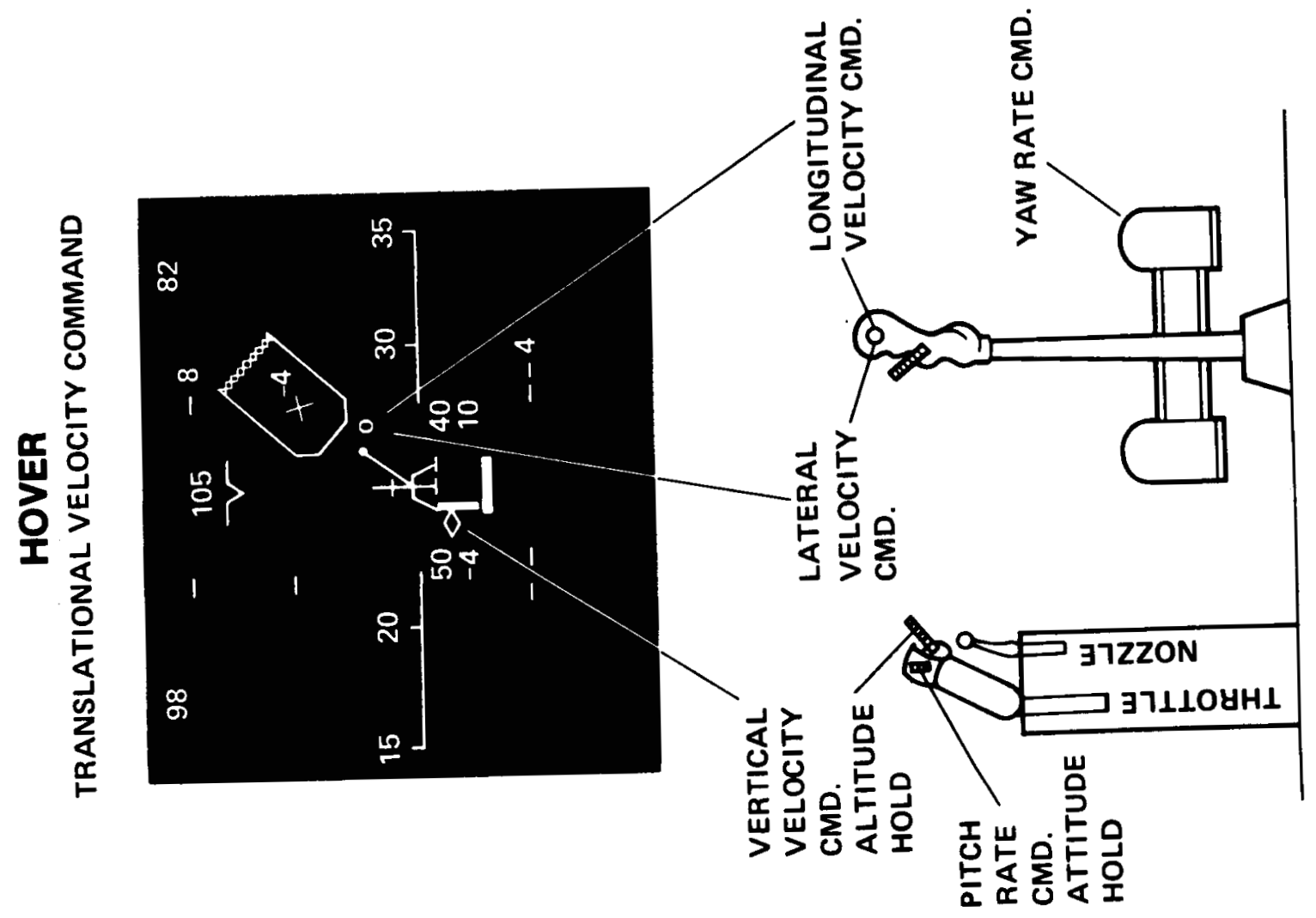

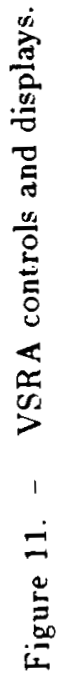

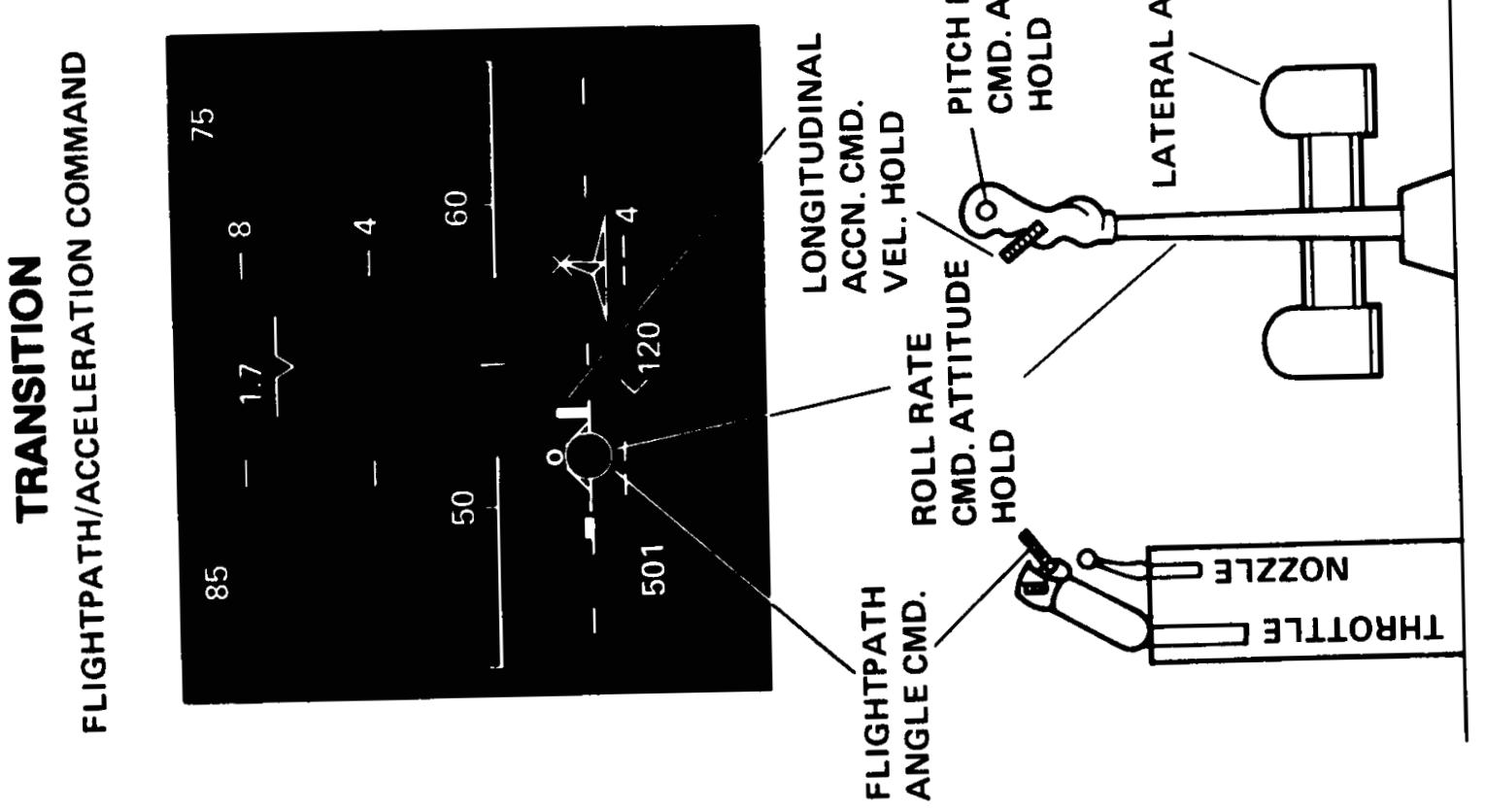

ORIGINAL PAGE IS 
ORIGINAL PAGE IS

DF POOR nTIITTY

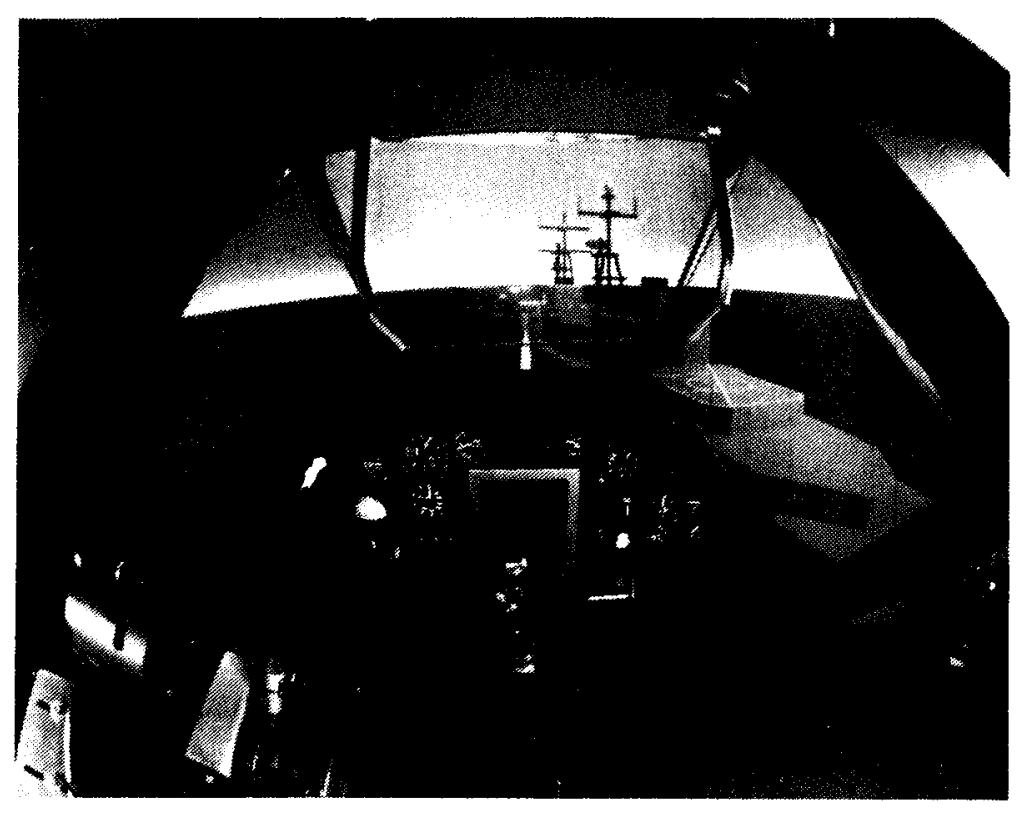

Figure 12. - VSRA simulation cockpit on VMS. 


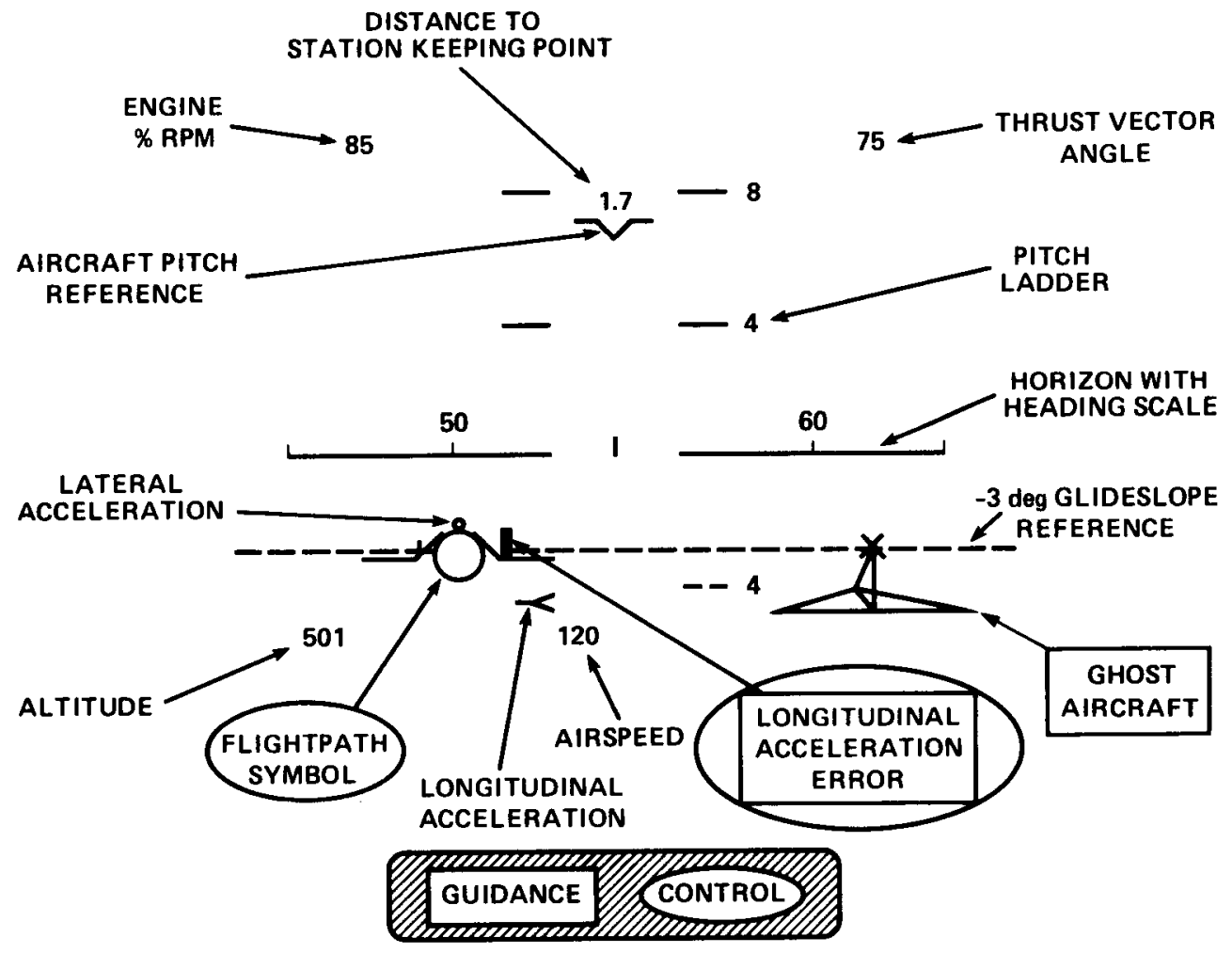

Figure 13. - HUD format in transition. 


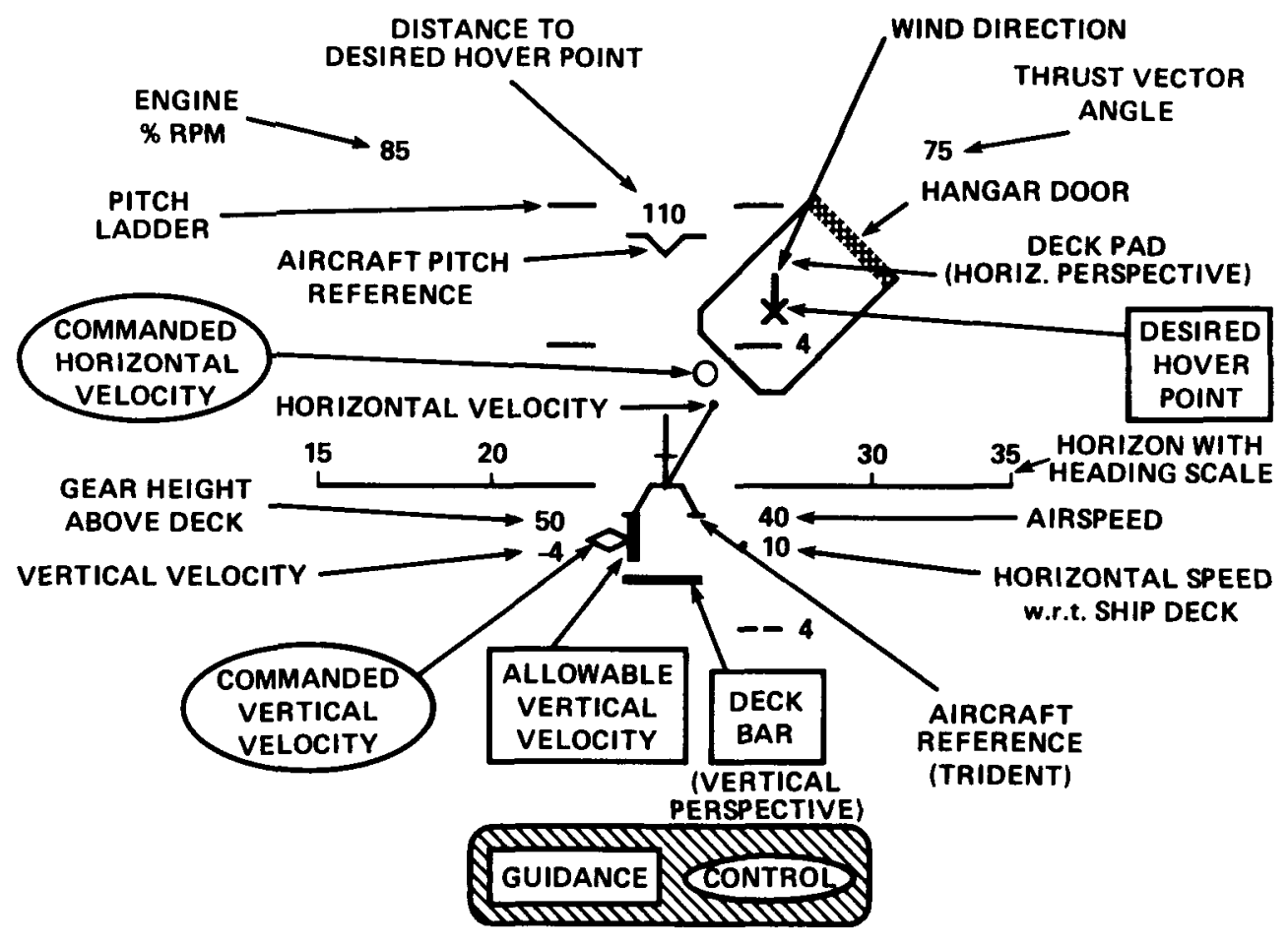

Figure 14. - HUD format in hover. 


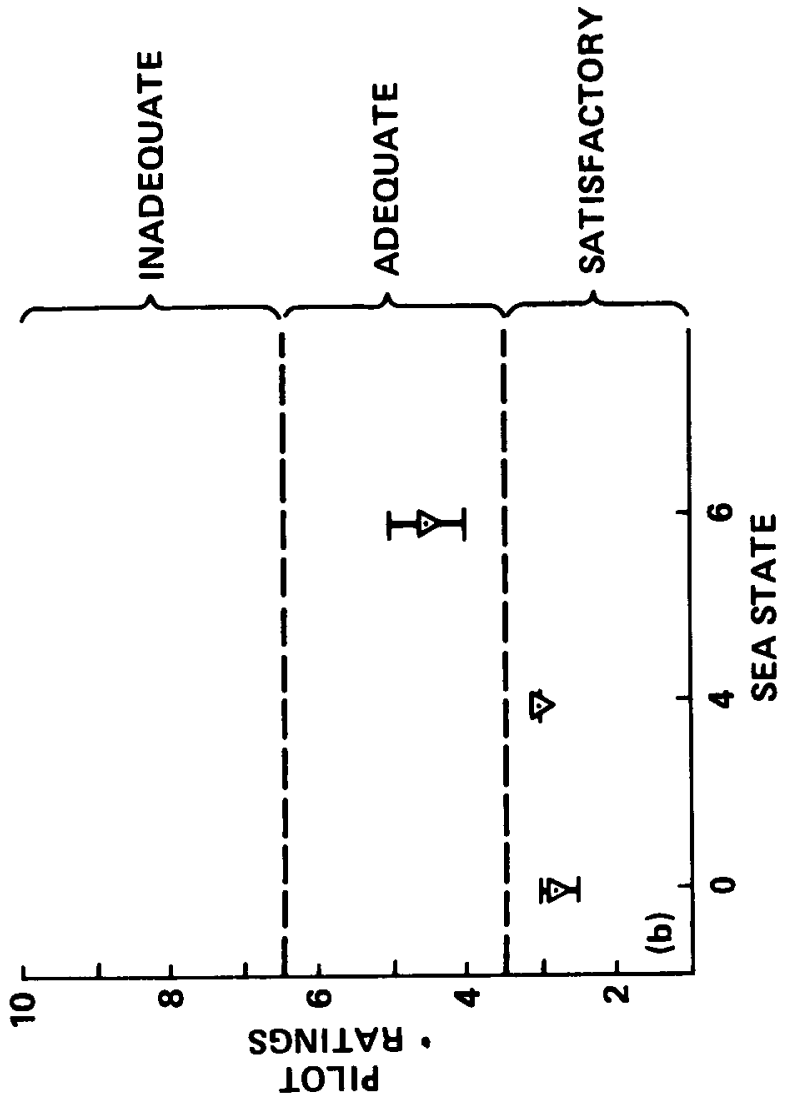

폴 


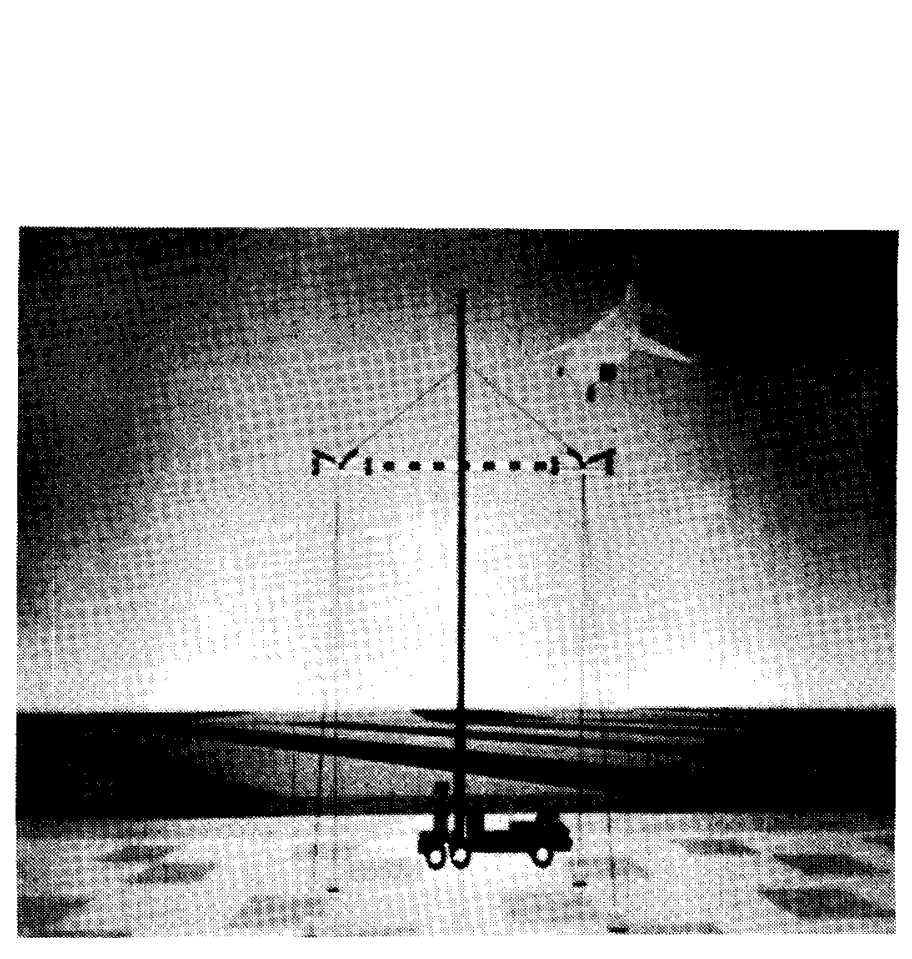

SIMULATION

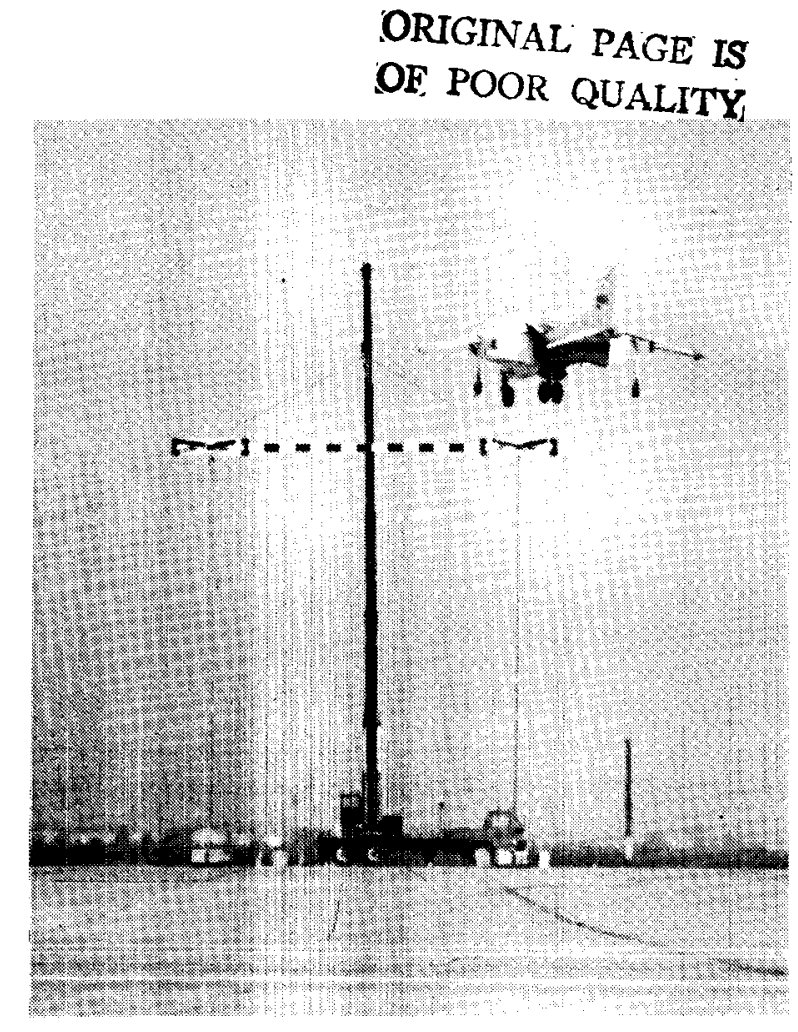

FLIGHT TEST

HORIZONTAL CONFIGURATION

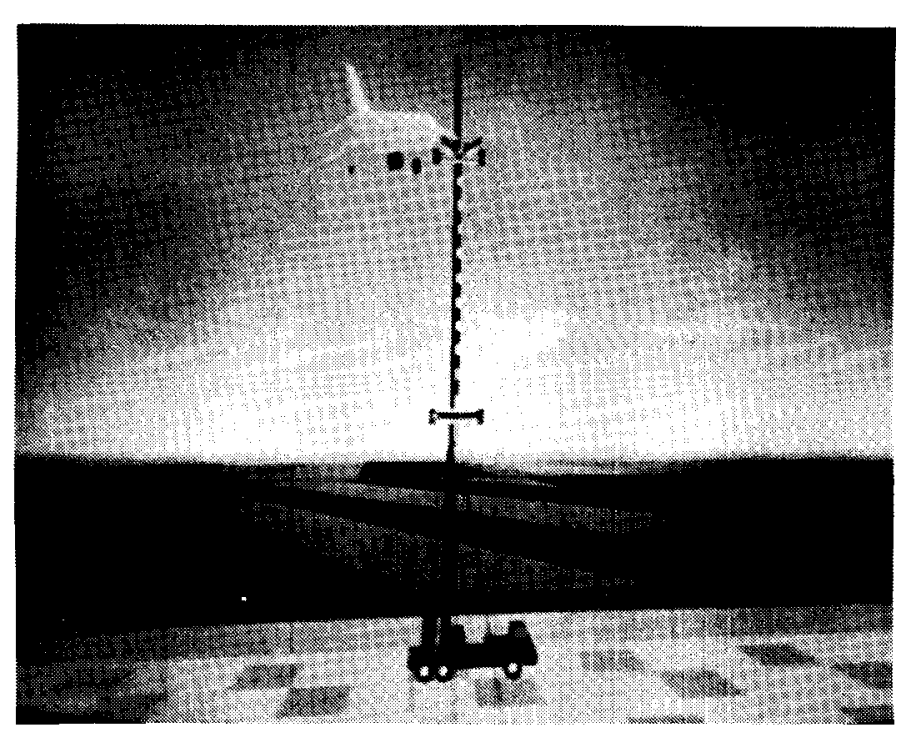

SIMULATION

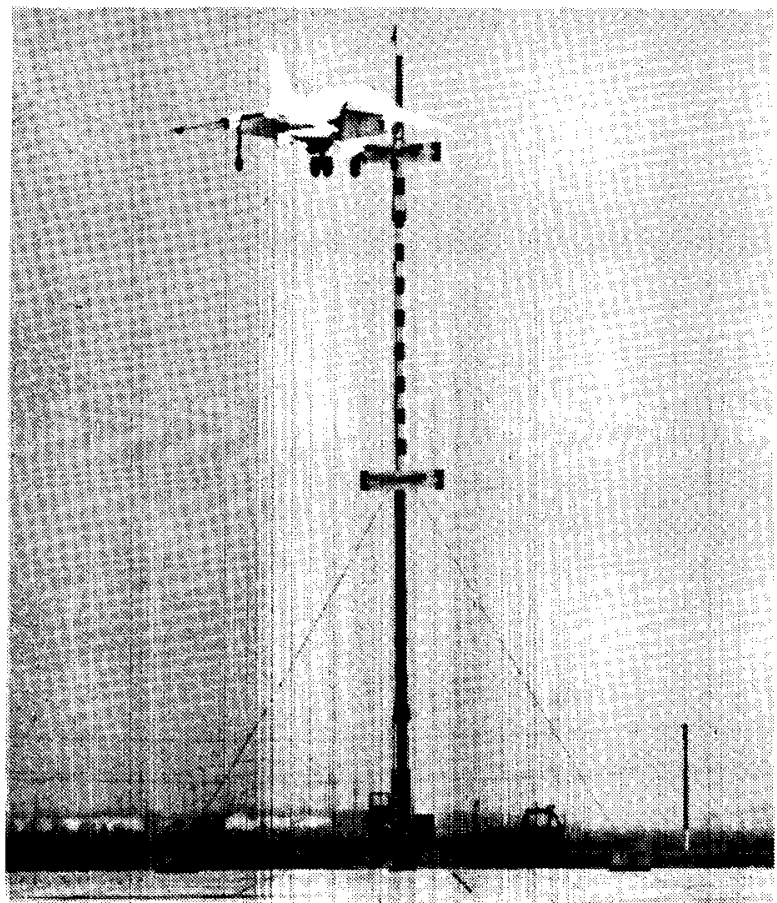

FLIGHT TEST

VERTICAL CONFIGURATION

Figure 16. - YAV-8B simulation fidelity test. 


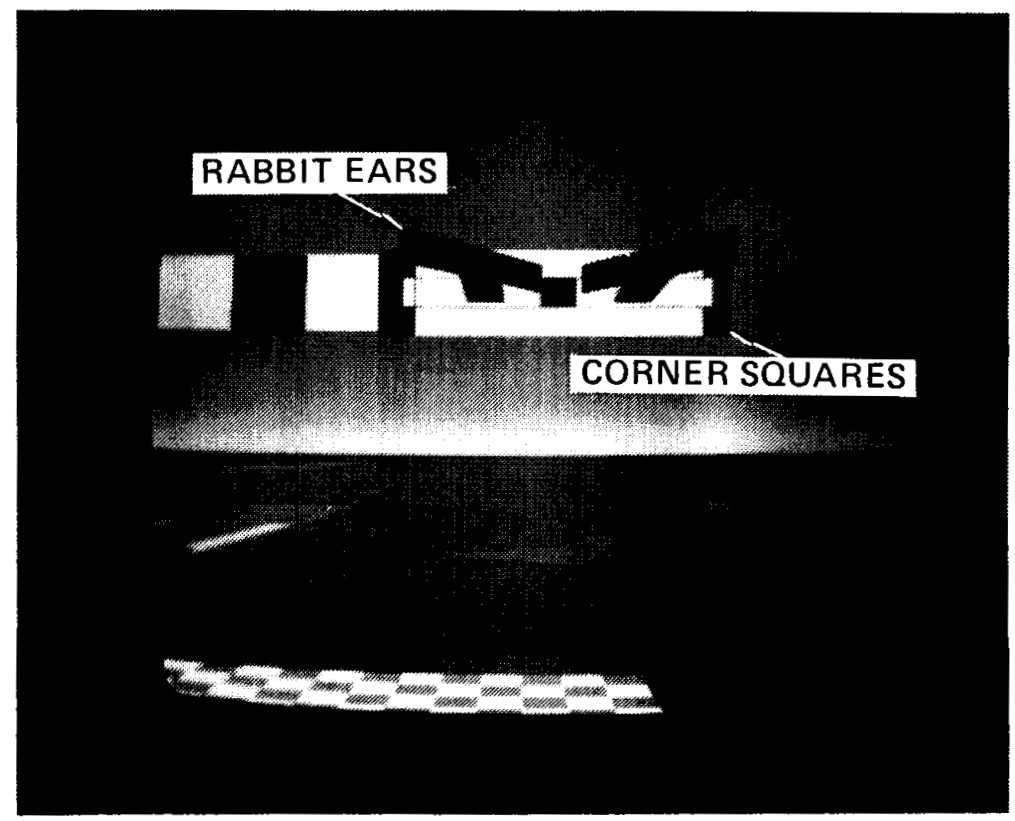

Figure 17. - Hover target close up.

ORIGINAL PAGE IS OF. POOR QUALITY 


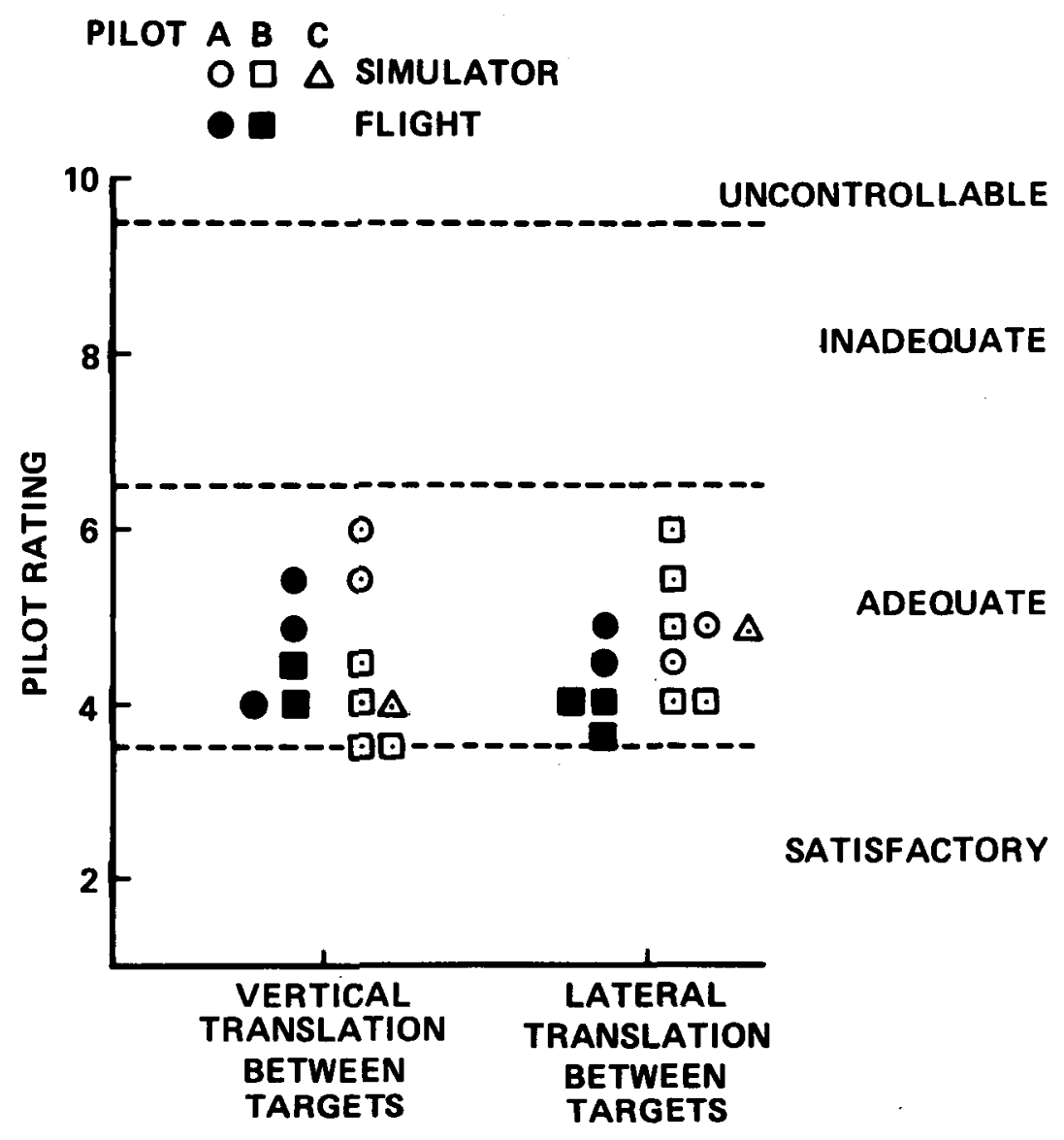

Figure 18. - YAV-8B precision hover flying qualities. 


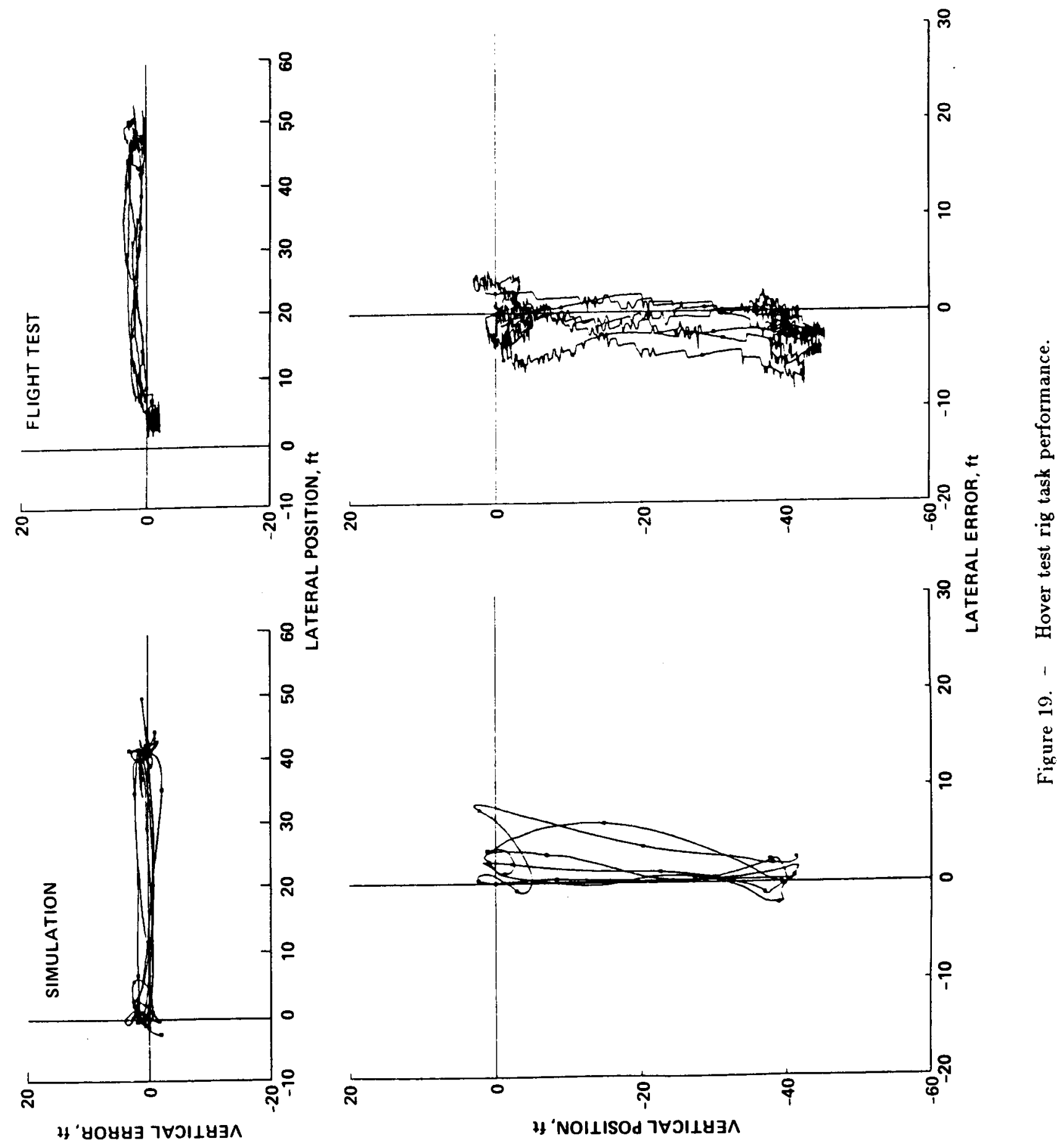




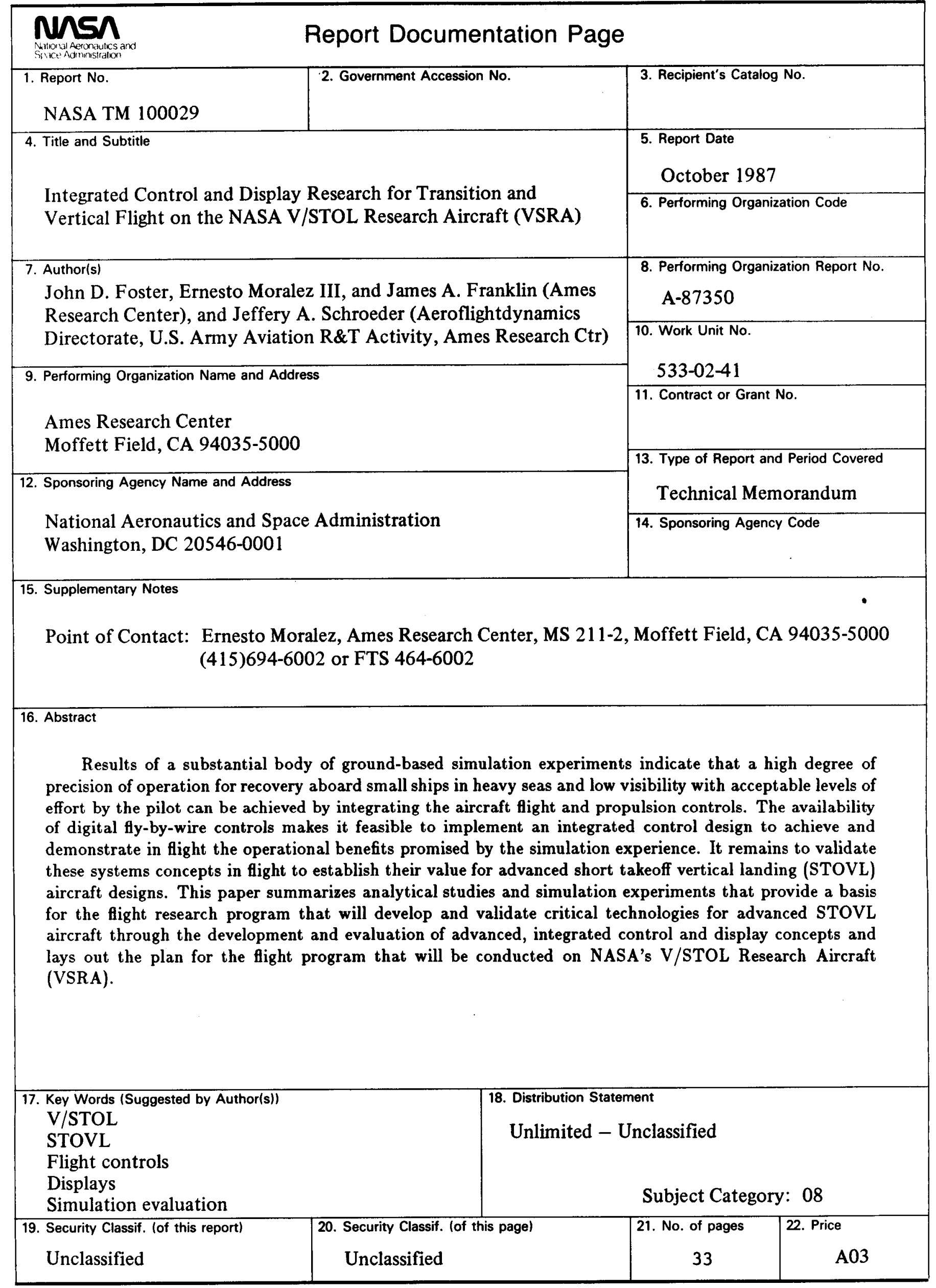

